\title{
Adipose tissue-derived mesenchymal stem cells for breast tissue regeneration
}

\author{
Mohammed A Banani ${ }^{1}$ Mohammed Rahmatullah11, Nawras Farhan1, Zoe Hancox² (D), \\ Safiyya Yousaf ${ }^{2}$, Zohreh Arabpour ${ }^{2}$ (D) Zoha Salehi Moghaddam², ${ }^{2,}$ Masoud Mozafari ${ }^{3}$ (D) \& \\ Farshid Sefat*,2,4 (iD) \\ ${ }^{1}$ Division of Surgery \& Interventional Science, University College London, London, NW3 2PS, UK \\ ${ }^{2}$ Department of Biomedical \& Electronics Engineering, School of Engineering, University of Bradford, Bradford, BD7 1DP, UK \\ ${ }^{3}$ Lunenfeld-Tanenbaum Research Institute, Mount Sinai Hospital, University of Toronto, Toronto, M5G 1X5, Canada \\ ${ }^{4}$ Interdisciplinary Research Centre in Polymer Science \& Technology (IRC Polymer), University of Bradford, Bradford, BD7 1DP, UK \\ *Author for correspondence: Tel.: +44 (0)1274 233 679; F.Sefat1@Bradford.ac.uk
}

With an escalating incidence of breast cancer cases all over the world and the deleterious psychological impact that mastectomy has on patients along with several limitations of the currently applied modalities, it's plausible to seek unconventional approaches to encounter such a burgeoning issue. Breast tissue engineering may allow that chance via providing more personalized solutions which are able to regenerate, mimicking natural tissues also facing the witnessed limitations. This review is dedicated to explore the utilization of adipose tissue-derived mesenchymal stem cells for breast tissue regeneration among postmastectomy cases focusing on biomaterials and cellular aspects in terms of harvesting, isolation, differentiation and new tissue formation as well as scaffolds types, properties, material-host interaction and an in vitro breast tissue modeling.

First draft submitted: 14 April 2020; Accepted for publication: 8 January 2021; Published online: 3 February 2021

Keywords: adipose tissue-derived stem cells $\bullet$ ADSCs $\bullet$ breast cancer $\bullet$ epithelial cells $\bullet$ mastectomy - microenvironment $\bullet$ reconstruction $\bullet$ scaffold $\bullet$ tissue engineering

Breast cancer is the commonest malignant disease and the fifth commonest cause of death among females worldwide with nearly 1.5 million new cases diagnosed each year (1.7 million new cases in 2012) [1,2]. Thus, it represents about $12 \%$ of all new cancer patients and 25\% of all malignant diseases in females [2]. In England, approximately 46,000 new cases are annually diagnosed with nearly $40 \%$ undergo mastectomy [3]. The risk of breast malignancy doubles each decade until reaching the menopausal period, after which there is a slower risk increment. Nevertheless, it is commoner in the postmenopausal period [2].

The National Institute for Health and Clinical Excellence (NICE) guidelines recommended the immediate breast reconstruction (IBR) for all patients undergoing mastectomy, however, significant comorbidities or the use of adjuvant therapy may rule out this option [4]. In fact, only $21 \%$ undergo IBR at their initial operation [5]. Mastectomy represents a life-altering morbidity with physical and psychological impacts that necessitates a multidisciplinary management [5]. Additionally, patients usually suffer from significant anxiety, depression, insomnia, suicidal ideas and feeling of shame [6]. Therefore, breast reconstruction relieves the sense and fear of disfigurement and improves the emotional and sexual well-being $[5,7]$. Those reasons, along with the limited breast-preserving surgery modalities, have led to a special motivation in the field of breast tissue engineering [6], as personalized treatments have a pivotal role in enhancing life quality and expectancy [8].

The incorporation of tissue engineering and stem cells revolutionizes the field of tissue regeneration [9], as this provides custom-designed solutions for tissue reconstruction and offers like-for-like tissue replacement without the adverse effects of immunosuppression or donor-site morbidity [10]. Adipose tissue-derived mesenchymal stem cells (ADSCs) are multipotent mesenchymal stem cells (MSCs) with similar features to bone marrow-derived MSCs (BMSCs) [11] (Figure 1). These cells are considered ideal for adipose tissue regeneration, as they proliferate and mature into adipocytes to restore or augment the lost volume [12], besides secreting essential growth factors

Future Medicine 


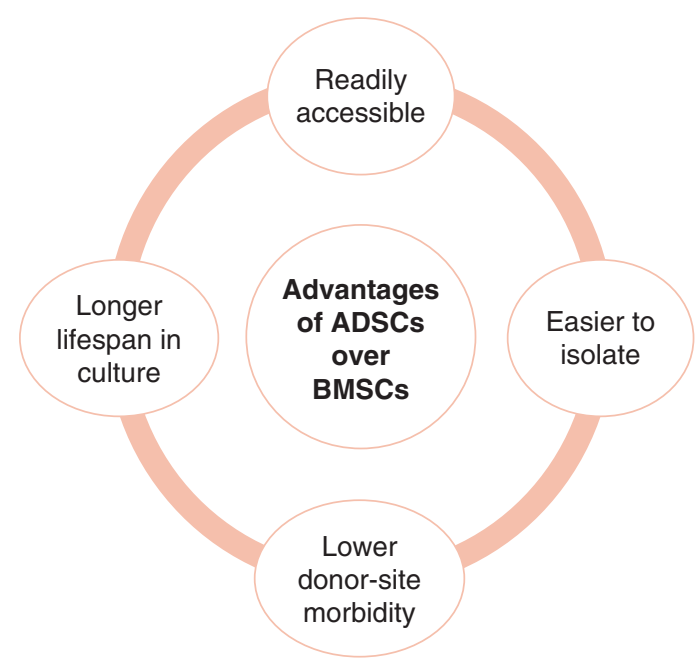

Figure 1. Advantages of adipose tissue-derived mesenchymal stem cells over in bone marrow-derived mesenchymal stem cells.

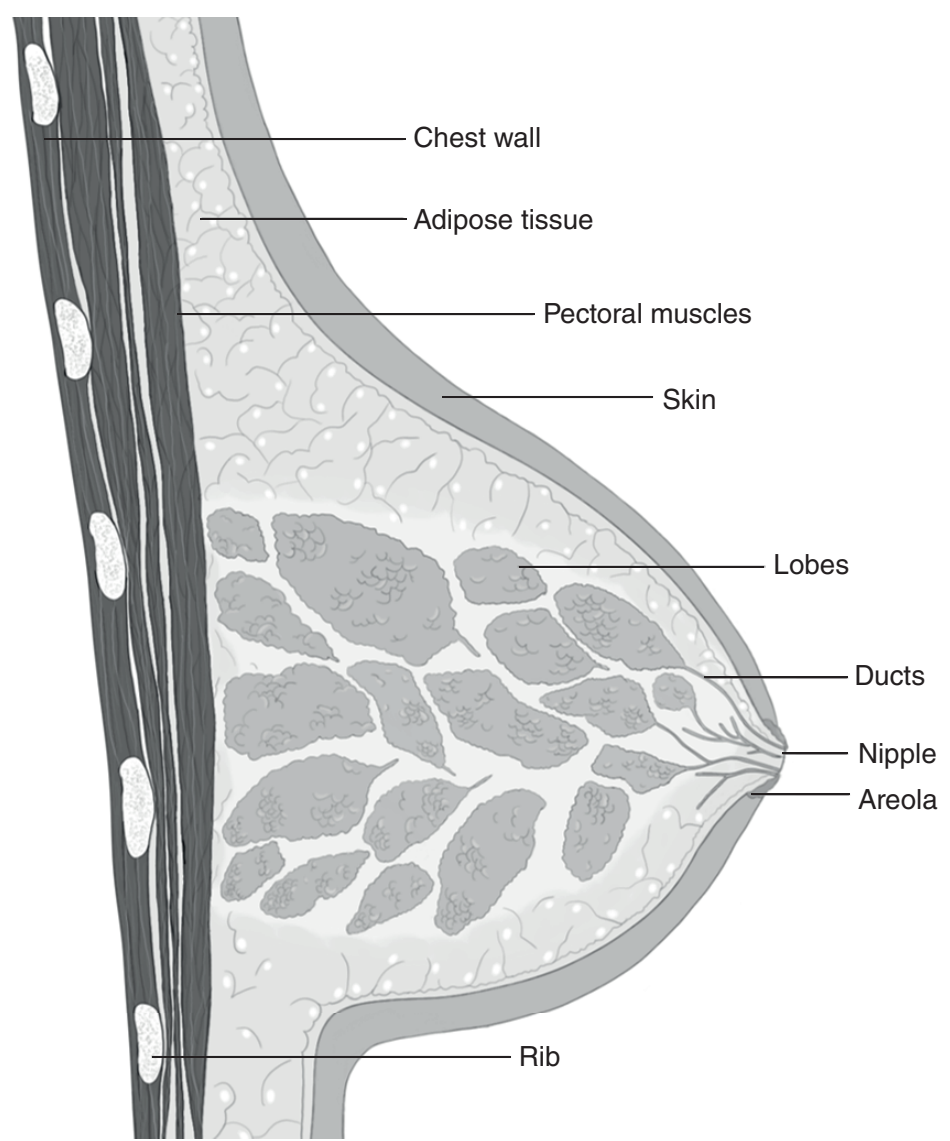

Figure 2. Anatomy of adult female breast. The major breast structures are the nipple-areola complex, the large ductal system and the terminal duct lobular units.

(i.e. VEGF) for angiogenesis and adipogenesis [9]. This explains the crucial role of ADSCs in maintaining regenerated tissue volume [5].

\section{Breast anatomy, histology \& development}

The breast is a complex dynamic organ, consists of various cell types that are actively interacting under the control of microenvironmental signals throughout the process of maturation [13]. The developmental stages are characterized by radical compositional, architectural and functional changes which are mediated by significant alterations in gene expression [14]. Anatomically, the breast consists of 15-20 lobes and each lobe consists of 20-40 lobules that are connected by ducts and comprise the mammary glands [6] (Figure 2). It is highly vascular and contains a 
Epithelial cell types

- Luminal cells

- Myoepithelial cells

\section{Stroma}

- Interlobular stroma

- Intralobular stroma

\section{Structure}

- Large ducts

- TDLUs
Figure 3. Normal breast tissue 'rule of two'.

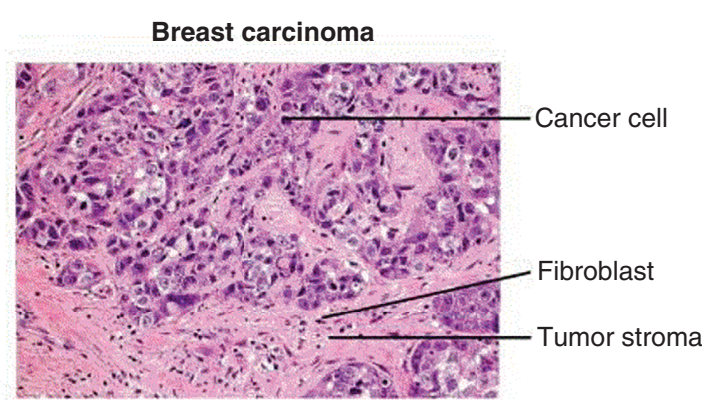

Figure 4. The normal and malignant breast histology. Hematoxylin and eosin staining of normal adult breast tissue [127]. The normal gland is a well-organized structure. The breast acini and ducts consist of a central lumen and are lined by polarized luminal epithelial cells (inner layer) and myoepithelial cells (outer layer). A basement membrane separates these two layers from the surrounding stroma and is composed of stromal extracellular matrix and stromal cells (i.e., fibroblasts and adipocytes). Basement membrane contains different types of proteins (mainly collagen type IV and laminin).

Reproduced from [19] with permission from Elsevier, copyright 2008 [18].

large number of lymphatic vessels and lymph nodes, which drain into the axillary and internal mammary lymph nodes [6,7,14]. A loose connective tissue layer allows the free movement of the breast over the deep fascia [7], while the suspensory ligament (Cooper's ligament) attaches the breast to the overlying skin and the underlying structures [15]. The size and weight of the breast differ significantly among individuals ranging from small-medium sized breasts $(\leq 500 \mathrm{~g})$ to large sized breasts $(750-1000 \mathrm{~g})[16]$.

Histologically, this specialized organ follows 'the rule of two' by being composed of two types of epithelial cells, stroma and main structures [17] (Figures $3 \& 4$ ). It encompasses glandular, ductal, connective and adipose tissues with numerous cell types, such as preadipocytes, adipocytes, epithelial cells, endothelial cells, MSCs, fibroblasts, myofibroblasts and leukocytes [18]. During puberty, the growth and development of the breast are governed locally by the paracrine reciprocal interactions between ductal epithelial cells and stroma, and systemically by the hormones produced by the pituitary gland and ovaries (i.e., estrogen and growth hormone are essential for mammary ductal morphogenesis) [13].

While during and after menopause, decreased levels of estrogen and progesterone caused by declining ovarian function leads to postmenopausal breast involution [14]. Consequently, breast lobules diminish in number and shrink in size resulting in a lower breast density [6].

\section{Epithelial cells interactions with extracellular matrix proteins}

Epithelial cells survival, proliferation, differentiation, polarity and invasive capacity are governed by cell-cell and cell-microenvironment interactions [18]. The cell-extracellular matrix (ECM) attachment has a critical role in epithelial differentiation, polarity and organization, as this is achieved when cell integrins bind to ECM collagen, laminin and fibronectin (i.e., $\alpha_{2} \beta_{1}$ integrins bind to collagen and laminin) [18-20]. For instance, in nonmalignant and malignant epithelial structures, ligation of $\beta 4$ integrin (which is induced via the interaction with laminin) regulates polarity and enhances cellular resistance to apoptosis regardless of the growth status [21]. That's why apoptosis of the mammary epithelial cells ensues when stimuli from integrin-ECM adhesion are absent [22]. 
Table 1. Factors controlling breast tissue properties.

\begin{tabular}{|c|c|c|}
\hline Factor(s) & Parameter(s) & Ref. \\
\hline The ratio of adipose to fibrous tissues & Density & [6] \\
\hline The breast skin envelope and adipose tissue & Size and shape & [7] \\
\hline The adipose tissue clusters and lobules that are distributed between fibrous and glandular tissues & Consistency, bulk and contour & {$[6,7]$} \\
\hline Cooper's ligaments & Support, shape and contour & [15] \\
\hline The glandular epithelium and ductal structures & Density and consistency & [6] \\
\hline
\end{tabular}

ECM remodeling is considered a prerequisite for acini formation, which is achieved by the activity of matrix metalloproteinases enzymes (MMPs) (i.e., MMP14, MMP13, MMP2 and MMP9) [23]. Moreover, the mechanical characteristics of the ECM govern the formation and organization of the polarized growth-arrested structures, as increased ECM density and stiffness disrupts the polarized organization of the acinar and ductal structures formed by epithelial cells $[23,24]$.

\section{Biomechanical properties of breast tissue}

Generally, the mechanical properties of the soft tissues involve a sophisticated combination of elasticity and viscosity that governs tissue deformation [15]. Breast viscoelasticity is governed by woman's age, hormonal levels, pregnancy, lactation, menstrual cycle and tumors formation [25]. Table 1 illustrates the role of different breast tissue components in controlling breast tissue properties. For normal breast, the elastic modulus (Young's modulus) of the fatty tissues is $3-20 \mathrm{kPa}$ and for the fibroglandular tissues is $3-44 \mathrm{kPa}$ [18]. These results were obtained using indentation or compressive force sonography, sonoelastography and magnetic resonance elastography [18].

Furthermore, the breast tissue is characterized by a tensile response that reveals a nonlinear stiffening at high deformation [15]. Malignant and benign breast tumors, when compared with normal breast tissue, are generally stiffer and exhibit a higher nonlinear increment in stiffness because they undergo collagen remodeling [15].

It is worth noting that the static and dynamic body forces applied to the breast are supported mainly by three structures: Cooper's ligaments, pectoralis fascia and the rib cage, which support tension loads, shear forces at breast base and compression loads, respectively [16].

\section{Current clinical practices for breast reconstruction}

Several factors should be considered when deciding the treatment approach for breast cancer, such as tumor stage and size, patient's general health status and comorbidities [6]. Surgical resection comprises two standard procedures, mastectomy and lumpectomy, which are selected according to breast tumor progression [6].

There are two factors determining the type and timing of the reconstructive procedure, patient's general health status and then patient's preference [6]. IBR following mastectomy has crucial advantages, which are: single operation, shorter hospitalization and better psychological and aesthetic outcomes [26]. However, all breast augmentation and reconstruction should be weighted for benefits and risks, as all patients have different requirements and some procedures may be suitable for some where others are not [27].

\section{Implant-based reconstruction}

Breast implant is a simpler procedure with shorter operation time [28]. It is either performed as a two-stage procedure that involves implantation of a tissue expander followed by replacement with a fixed-volume permanent implant, or a single-stage fixed-volume permanent implant [29]. Many women commonly choose silicone as their option for implants, but saline is another option less popularly chosen, as women prefer the lower expenses and feel of the silicone implants, despite the complications possible [30].

This procedure is associated with several complications that may lead to implant failure (Table 2), as the reported incidence of implant removal is $20 \%$ within $8-10$ years [31], with complication probability increasing drastically in patients with high-stage breast cancer undertaking radiation therapy [32].

\section{Autologous flap reconstruction}

Breast reconstruction using autologous tissues offers more durable results, greater consistency, better aesthetic outcome and better tolerance to radiotherapy and obviates the complications associated with implants [26]. Autologous flap reconstruction involves the removal of healthy tissue from a location of the patient's body, to be relocated to 


\begin{tabular}{|c|c|c|}
\hline Complication & Description & Ref. \\
\hline \multirow[t]{3}{*}{ Short-term complications } & Hematoma, seroma & [28] \\
\hline & Infection: may lead to intractable cellulitis and subsequent implant removal & [31] \\
\hline & Mastectomy skin flap necrosis & [28] \\
\hline \multirow[t]{10}{*}{ Long-term complications } & Pain in the local surgery area & [77] \\
\hline & Breasts' asymmetry & [32] \\
\hline & Loss of nipple sensation & [7] \\
\hline & Implant wrinkling or ripple formation & [32] \\
\hline & Implant malposition, displacement or deformation & {$[18,32]$} \\
\hline & Silicone or saline leakage & [7] \\
\hline & Implant deflation, rupture or extrusion & {$[18,28]$} \\
\hline & Capsular contracture: due to foreign body reaction & [7] \\
\hline & Post-radiotherapy complications: as high as $60 \%$ with an increased risk of implant extrusion and capsular contracture & [31] \\
\hline & Scar tissue formation & [77] \\
\hline
\end{tabular}

Table 3. Autologous flaps for postmastectomy breast reconstruction.

\begin{tabular}{|ll}
\hline Classification & Type \\
\hline Pedicled flaps & Latissimus dorsi flap \\
\hline Free flaps & Pedicled Transverse rectus abdominis musculocutaneous flap \\
& Free Transverse rectus abdominis musculocutaneous flap \\
& Deep inferior epigastric artery flap \\
& Superficial inferior epigastric artery flap \\
& Superior gluteal artery perforator flap \\
& Inferior gluteal artery perforator flap \\
& Transverse musculocutaneous gracilis flap \\
\hline
\end{tabular}

Reproduced from [35].

the breast, this has been used effectively to create a natural feeling breast and hence works towards increasing the confidence of the patient [30]. However, these procedures are more complex with longer recovery and are associated with potential donor and recipient-site morbidity [28]. Consideration of donor-site tissue collection is vital, as removing tissue from some sites could result in the formation of hernias [33], for example removing flap-tissue from the lattisumus dorsi could result in a lumbar hernia because of the reduced layers of tissue, requiring further surgery to insert a mesh to keep the hernia from rupturing [34].

According to their relation to the donor-site, tissue flaps can be classified into two main categories: pedicled flaps and free flaps [35] (Table 3). Pedicled flaps is tissue which have the blood vessels joined to in an intact form, whereas free flaps on the other hand have to be connected to the blood supply of the breast due to complete flap removal from the donor site [30].

Free flaps are carried out more successfully, sourcing the donor sites from adipose rich areas, such as the abdomen flaps to be moved to the breast area, the tissue having a higher chance of survival with less likely reduction in strength at the donor-site [33].

\section{Cellular breast restoration}

This approach can be achieved through autologous lipotransfer or adipose tissue engineering (Table 4).

\section{Adipose tissue-derived stem cells}

Adipose tissue is normally found under the skin and consists of fat cells (adipose cells or adipocytes) which are specialized in the production and maintenance of large fat globules. Adipose tissue is an abundant, accessible and replenishable source of adult somatic stem cells. ADSCs prevent severe graft-versus-host disease in vitro and in vivo and to be genetically stable in long-term culture and therefore they have great potential applications for the repair and regeneration of acutely and chronically damaged tissues [36]. MSCs were named over 25 years ago to represent a class of cells that can be isolated from many adult tissues such as bone marrow, adipose tissue, cord 
Table 4. Different approaches for cellular breast restoration.

\begin{tabular}{|c|c|c|}
\hline Procedure & Description & Ref. \\
\hline Autologous lipotransfer & $\begin{array}{l}\text { It involves harvesting and relocating adipose tissue to reconstruct the breast without using a } \\
\text { scaffold and is considered as a limitless source for reconstructing soft tissues. } \\
\text { Advantages: } \\
\text { - Inexpensive procedure. } \\
\text { - Less invasive than flap or implantation surgeries, involving less risks. } \\
\text { - Breast size and shape is restored to appear and feel more natural. } \\
\text { - Enhanced engraftment, volume retention and long-term survival with improved healing, } \\
\text { angiogenesis and collagen synthesis (by the effect of ADSCs growth factors: TGF- } \beta 1, \text { IGF and } \\
\text { VEGF). } \\
\text { Limitations: } \\
\text { - Poor clinical results, as it is associated with } 50-70 \% \text { fat graft resorption, which can be } \\
\text { attributed to poor revascularization. } \\
\text { - The harvested adipocytes cannot proliferate because they are mature and terminally } \\
\text { differentiated. } \\
\text { - Formation microdeposits of serum calcium that interfere with radiological tumor diagnosis. } \\
\text { Cell-assisted lipotransfer: } \\
\text { - This modification involves supplementation of the fat graft with ADSCs or stromal vascular } \\
\text { fraction. }\end{array}$ & {$[5-7,28,33-36,77,81]$} \\
\hline $\begin{array}{l}\text { Bioengineering in situ } \\
\text { adipogenesis }\end{array}$ & $\begin{array}{l}\text { It involves recruitment of resident surrounding preadipocytes by changing the tissue } \\
\text { microenvironment and using acellular constructs to ultimately achieve de novo fat formation. }\end{array}$ & [7] \\
\hline $\begin{array}{l}\text { Bioengineering de novo } \\
\text { adipogenesis }\end{array}$ & $\begin{array}{l}\text { It encompasses isolation and culturing of preadipocytes and capillary endothelial cells. These cells } \\
\text { are then seeded in a biodegradable polymeric scaffold supplemented with suitable angiogenic } \\
\text { and adipogenic growth factors, to be transferred to tissue sites. }\end{array}$ & [37] \\
\hline
\end{tabular}

and peripheral blood, fallopian tube, fetal liver and lung. MSCs can be defined as plastic-adherent cells that have a multipotent differentiation capacity in vitro and can differentiate into osteocytes (bone), chondrocytes (cartilage) and adipocytes (fat) cells [37] (Figure 5).

MSCs can also be defined to have a fibroblast-like morphology as well as being able to form collonies in vitro. They can directly differentiate into mesodermal lineages and also have the ability to transdifferentiate into ectoderm and endoderm lineages [38]. ADSCs gained a lot of interest over the past years for their unique multilineage differentiation potential and immunomodulatory properties, hence, used for many different applications. They are being viewed from a traditional cell therapy perception as well as contributing to a new tissue formation through terminal differentiation or modulation of endogenous repair processes as they home to sites of injury and/or of inflammatory responses via paracrine signaling [39].

ADSCs modulate the immune system by applying regulatory effects on various immune cells and can modulate many T-cell functions including cell activation. They have the ability to secrete anti-inflammatory cytokines, expand regulatory $\mathrm{T}$ cells and improve the outcome of allogeneic transplantation via promoting hematopoietic engraftment [40].

In particular, the ADSCs are a highly promising cell type for clinical applications due to its ease of isolation from an abundant source [40]. However, stem cell implantation into the breast should be done so cautiously, as Donnenberg et al. have shown that ADSCs can accelerate the growth of breast cancer cells, therefore the patient should be free of all cancer and passed cancer remission before ADSCs tissue engineering procedures begin [41].

\section{Isolation \& culture}

ADSCs can be isolated by a variety of techniques, grown and expanded using numerous reagents and differentiated in a range of media, proteins and small molecules (Figure 6). Bone marrow has been commonly considered as the main source to isolate MSCs, but it has some considerable negative issues for the patient and also some disadvantages compared with other tissue types. However, harvesting ADSCs have shown promising benefits attributed to the abundance of adipose tissues and therefore they can be collected in higher numbers as well as from different locations of the body [42].

In general, there are two techniques for harvesting adipose tissue; liposuction and resection or needle biopsy where the tissue is first washed with phosphate-buffered saline to remove any debris, then placed on culture plates in a sterile condition to digest the tissue by chopping the fatty tissue into fine pieces and incubated while in collagenase then centrifuged to separate the mature adipocytes that are floating and to remove the non-adherent cells. The 


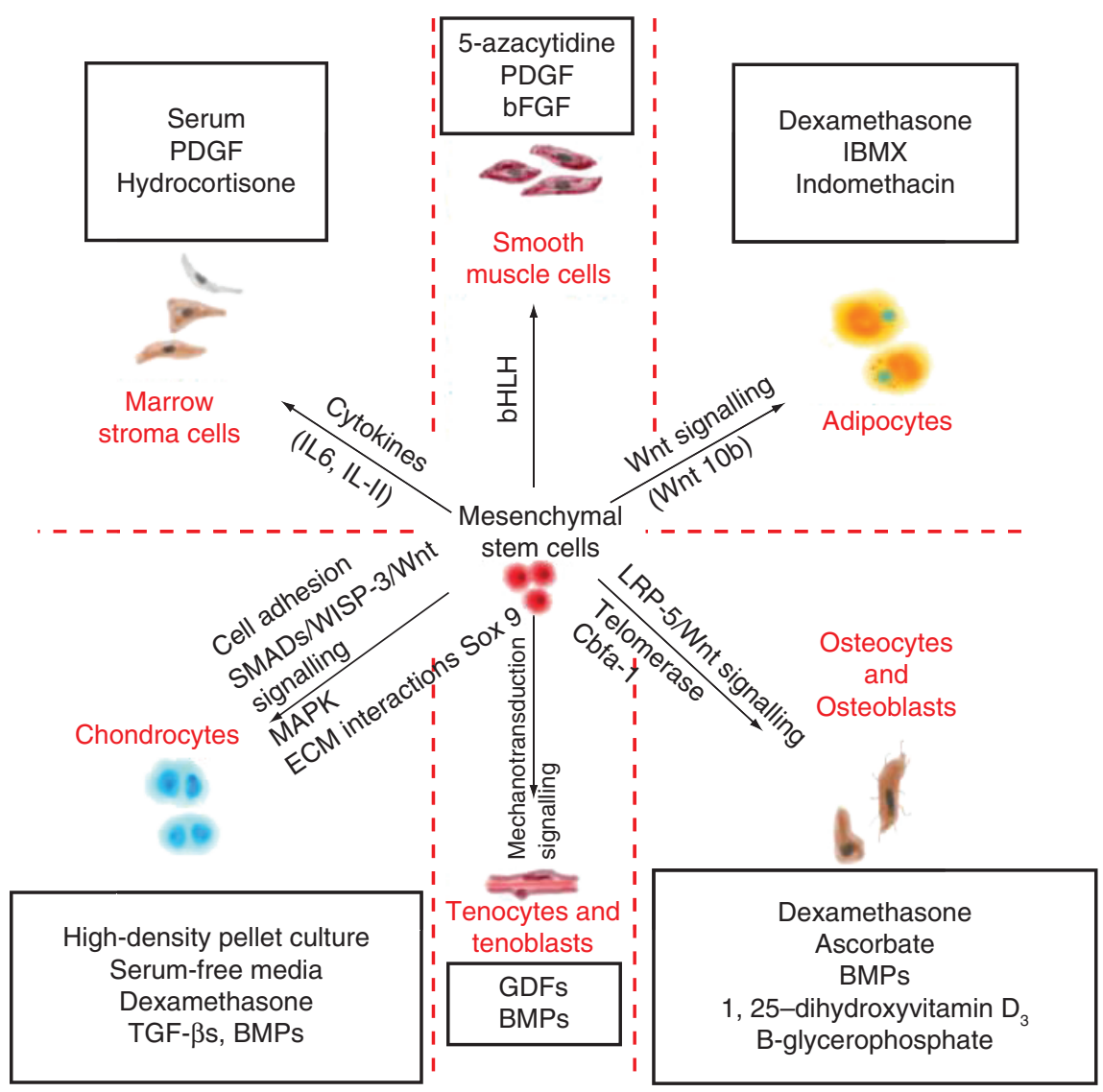

Figure 5. Culture conditions for the differentiation of mesenchymal stromal cells.

Reproduced from [74] with permission from Elsevier, copyright 2008 [74].

ECM: Extracellular matrix; PDGF: Polylactic-co-glycolic acid.

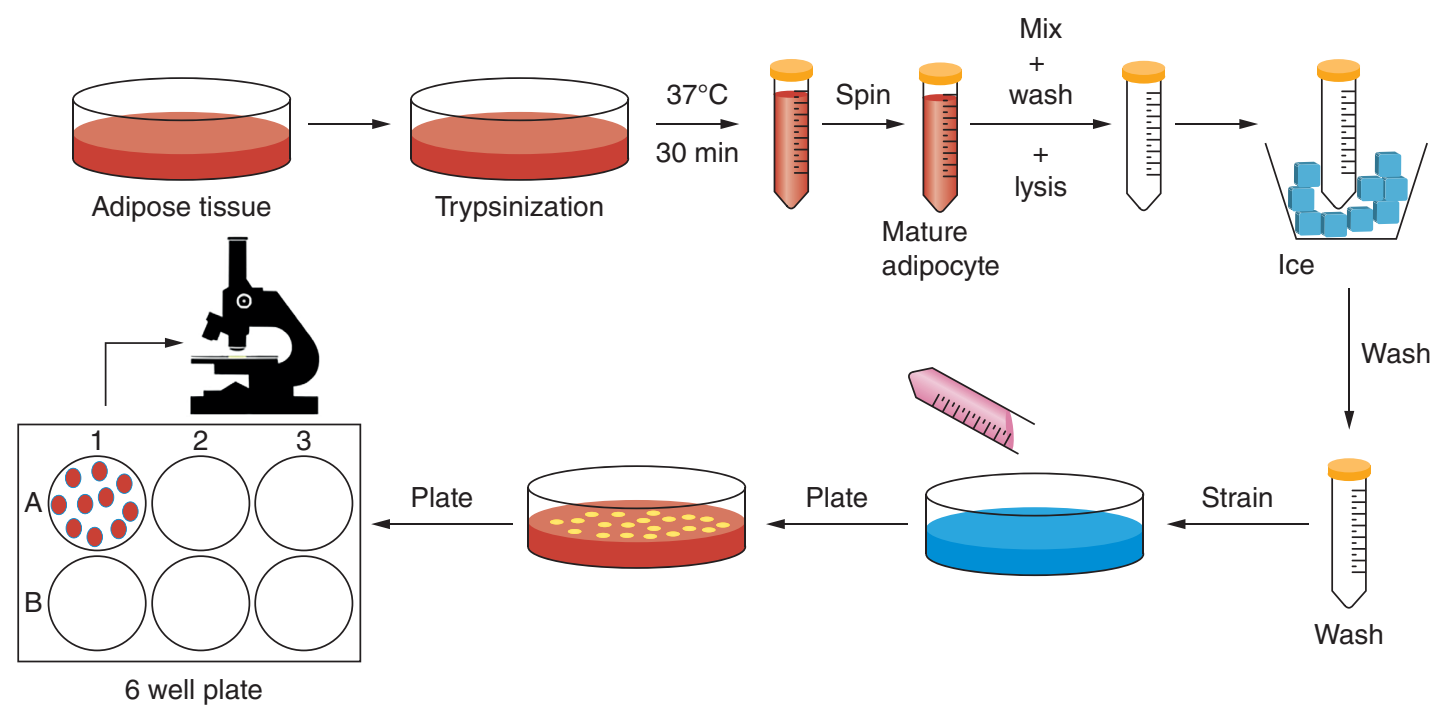

Figure 6. Scheme for processing of adipose tissue and isolation of adipose tissue-derived stem cells. 
cultured cells are then recultured for 3-4 weeks while being passaged to proliferate and expand in culture followed by cryopreservation and controlled freezing and finally long-term freezing storage [42].

\section{Growth \& differentiation}

ADSCs are self-renewing cells that can be used clinically to replace or repair damaged tissues. Currently, it is clear that the clinical promise of ADSCs is supported by their attractiveness associated with self-renewal and pluripotency to commit, differentiate, and mature into specific phenotypes under the control of cell-intrinsic signaling mechanisms [43]. The process of ADSCs differentiation can be achieved by the use of transcription factors such as adipocyte determination and differentiation factor 1 and adipocyte-specific transcription factors (C/EBP $\alpha)$ under specific micro-environmental conditions [43].

\section{Adipogenesis}

ADSCs have the capability to differentiate into a number of cell types including adipocytes, osteocytes and chondrocytes. The adipocytes phenotype is characterized by intracellular accumulation of lipid droplets as well as transcription of adipocyte-specific genes. ADSCs differentiate to form adipocytes, the cells responsible for the synthesis and storage of fat or could also be named as generation of lipid-droplet bearing adipocytes. Differentiation markers of adipogenesis are important for the identification and isolation of differentiated adipocytes. Adipogenesis is a process whereby ADSCs or preadipocytes differentiate to acquire phenotypic characteristics of mature adipocytes [43]. Adipogenesis is induced in the presence of isobutyl-methyl-xanthine which can involve in phosphodiesterase inhibition, followed by PKA activation, and ultimately, leads to the activation of C/EBP $\alpha$ [43].

\section{Adipogenic differentiation \& epigenetics}

Epigenetic refers to heritable changes involving the gene expression without any changes in the DNA sequences. The interaction between transcription factors and genes are modulated by DNA methylation which regulates the gene expression by modifying the chromatin or nuclear architecture. As mentioned above, adipogenesis is a highly regulated process that involves several transcription factors and researches have shown that DNA Methylation as well as other factors is responsible for the regulation of adipogenic differentiation [44].

\section{Enhancing the differentiation}

Adipogenic differentiation can be induced using a culture medium containing isobutyl-methyl-xanthine, indomethacin and dexamethasone until mature adipocytes are obtained (after 12-14 days). The cells are then fixed by formalin solution and ethanol and air dried before dye staining. It is possible to tune or control the amount of differentiation by either addition of more adipogenic differentiation media, addition of rabbit serum (which induces adipocyte-like differentiation) or using different PPAR- $\gamma$ agonists [45].

\section{Cell surface marker expression}

According to the International Society for Cellular Therapy standard criteria, expression of specific set of cell surface markers is one of the essential ADSCs' characteristics. ADSCs constitute a heterogeneous population of cells in terms of their morphology and expression of surface antigens and this is the reason why there hasn't been an identified specific surface marker for the ADSCs [46]. The cells which show a positive expression for CD29, CD44, CD73, D90, CD105 and negative expression of CD14, CD34, CD45 and HLA-DR are considered as MSCs [46].

\section{Growth factors}

ADSCs can be influenced by different growth factor receptors that have been identified on their surface. Growth factor receptors such as: EGFR, bFGFR, IGFR, DGFR, TGFRI and RII have been reported to be important for MSCs self-renewal and differentiation [47].

\section{Challenges facing adipose tissue engineering for breast regeneration Cell survival \& vascularization}

Ensuring adequate nutrition and oxygenation have been recognized as a critical challenge in tissue engineering field in general and breast tissue engineering in particular attributed to the fact that the higher the volume/surface ratio the heavier the demand of adequate vascular supply [48]. Hence, vascularization remains as a major stumbling block in the way of ensuring long-term survival of the engineered tissue and an enhanced tissue configuration to emulate the $3 \mathrm{D}$ structure of the removed breast [48]. 
Better understanding of the close correlation between adipose and vascular tissue is a key to achieve the desired clinical translation of adipose tissue engineering. It is crucial to note that angiogenesis process occurs before the adipogenesis based on findings during embryological development, wound healing as well as experimentally [7]. The accumulation of fat after involution of a capillary hemangioma and the presence of adipose cells after the foundation of vascular connections act as vivid examples. However, there is no direct conjunction between endothelial cells and preadipocytes as cellular interactions are fostered via secreted or matrix-bound factors instead [7]. The action of such factors, which are produced by microvascular endothelial cells, was demonstrated to promote the proliferation and differentiation of pre-adipocyte during adipogenesis [49]. Furthermore, it has been shown that the adult adipose tissue tends to secrete growth factors and hormones which believed to be proangiogenic, in turn [50,51]. Thus, it is essential to consider the intimate relationship between both processes while shaping the way towards adipose tissue engineering.

Findlay et al. carried out a study, in order to increase the volume of vascularized adipose tissue that could be produced, reaching for a solution to increase the amount of breast tissue that can be reconstructed [52]. To test their theory, they created chambers subcutaneously within pig superficial circumflex pedicle, inserting free fat grafts, poly (L-lactide-co-glycolide) sponge, muscle and vascular pedicle or leaving the vascular pedicle by itself [52]. Findlay et al. found that all the chambers within 6 weeks, had suffused with new tissue, which was also sufficiently supplied with blood from the arteriovenous pedicle [52]. This indicating that adipose tissue can be sufficiently scaled to fill a wanted cavity, and if located near or attached to a pedicle can become vascularized. Yuan and Ogawa have shown that mechanical forces can be detrimental to the growth of adipose cells, as opposed to musculoskeletal tissue that seems to be encourages by mechanical forces [53]. Indicating that Findlay et al.'s study could have obtained its success, by limiting the mechanical stresses exhibited to the chambers produced in the superficial circumflex pedicle [53].

On the other hand, adipose tissue is highly vascularized, with a two- to three-times resting blood flow rate more than that of skeletal muscles and the existence of such an extensive vascular network guarantees the delivery of nutrients via simple diffusion [6]. Yet, it is limited within an approximately $150 \mu \mathrm{m}$ in vivo distance which means that the metabolically active cells beyond that distance are prone to hypoxia unless we can warrant a well-established vascular network in the engineered tissue mimics that of the natural organ to ensure application of adipose tissue engineering practice [6]. Many approaches have been pursued to promote vascularization and angiogenesis, albeit unfettered of limitations, see Table 5.

\section{Volume-skin coverage coordination}

There is no one-size-fits-all approach in breast restoration procedures as those have to be considered in a case-bycase manner regardless the used materials whether implant-based, autologous, or engineered tissue components. For better aesthetic results, the required volume for restoring breast mound has to be known before undergoing reconstructive surgery and this practice is still challenging as it is surgeon-reliant and often require a high degree of experience [7]. However, utilizing tissue engineering modalities allow an opportunity of predetermining the desired shape and size of the restored breast by determining the scaffold shape and cell numbers, for instance, especially if 3D imaging techniques are embraced to produce patient-specific breast models. Nevertheless, further adjustments have to be included to advance the level of personalization [7].

\section{Large animal model}

Small animal models are frequently employed to test the practical implication of adipose tissue engineering and its workability. However, it is preposterous to use similar species when considering mammary tissues, hence, larger animal models should be utilized but how similar the outcome to the humans would be questionable here [6]. The anatomy, histology and hormonal susceptibility of large animal models are quite relevant to that of humans along with providing an adequate area to contain large size implants [6,54]. Many factors have to be considered while evaluating the right animal model for a particular study as animals required to test large subcutaneous constructs should have similar skin and subcutaneous tissues to that of human, for instance [6]. Additionally, blood vessels must have a satisfactory caliber to allow anastomosis for microsurgery maneuvers, a suitable tissue structure is required to permit attaining, isolation and culturing of pre-adipocytes. The size of animal must be large enough to effectively demonstrate convection and diffusion-dependent transport with a reasonable gross morphology to insert the construct without affecting the animal's ability to move or its lifestyle. Growth rate and lifespan has to be borne in mind also, as a rapid weight gain may deter the ability to monitor the implant and a shorter life expectancy 
Table 5. Biomaterial-derived scaffolds investigated for adipose and/or breast tissue regeneration.

\begin{tabular}{|c|c|c|}
\hline Type of scaffold & Type of material & Ref. \\
\hline \multirow{18}{*}{ Synthetic scaffolds ${ }^{\dagger}$} & 1. Polylactic acid & 1. $[5,6,28,41-44]$ \\
\hline & 2. Polyglycolic acid & 2. $[6,7,42,43]$ \\
\hline & 3. Polylactic-co-glycolic acid & 3. $[5,7,28,37,42-44]$ \\
\hline & 4. Polyethylene & 4. $[37,45]$ \\
\hline & 5. Polyethylene glycol & 5. $[5-7,28,42-44]$ \\
\hline & 6. Polycaprolactone & 6. $[5,6,28]$ \\
\hline & 7. Poly-I-lactic acid & 7. [5] \\
\hline & 8. Polytetrafluoroethylene & 8. $[6,7,37,44,45]$ \\
\hline & 9. Polyethylene terephthalate & 9. $[42,44]$ \\
\hline & 10. Polypropylene & 10. $[28,42]$ \\
\hline & 11. Polyurethane & 11. [28] \\
\hline & 12. Polymethylmethacrylate & 12. $[37,45]$ \\
\hline & 13. Polydimethylsiloxane & 13. $[37,45]$ \\
\hline & 14. Polyanhydride & 14. [6] \\
\hline & 15. Polyamino acid & 15. [6] \\
\hline & 16. Polyortho ester & 16. [6] \\
\hline & 17. Fluoropolymers & 17. [43] \\
\hline & 18. Silicones & 18. $[37,43]$ \\
\hline \multirow[t]{10}{*}{ Natural scaffolds $\ddagger$} & 1. Adipose-derived ECM & 1. $[42,43]$ \\
\hline & 2. Collagen & 2. $[5-7,18,28,37,42-45]$ \\
\hline & 3. Decellularized human placenta & 3. [43] \\
\hline & 4. Fibrin & 4. $[6,37,42-45]$ \\
\hline & 5. Gelatin & 5. $[5,28,42,43]$ \\
\hline & 6. Hyaluronan & 6. $[6,7,28,37,41-45]$ \\
\hline & 7. Matrigel & 7. $[6,18,42-44]$ \\
\hline & 8. Silk & 8. $[5,18,28,42,43]$ \\
\hline & 9. Alginate & 9. $[5-7,28,44]$ \\
\hline & 10. Chitosan & 10. [6] \\
\hline Biological scaffolds & Decellularized matrix & {$[5,28,37,42,45]$} \\
\hline \multirow[t]{7}{*}{ Injectable scaffolds } & Alginate / o-carboxymethyl chitosan & 1. [5] \\
\hline & Polylactic-co-glycolic acid / hydrogel & 2. [5] \\
\hline & Alginate / polyvinyl alcohol with the inclusion of fibrin nanoparticles & 3. [5] \\
\hline & Alginate / collagen & 4. [5] \\
\hline & Natural scaffolds: alginate, chitosan, hyaluronic acid, collagen, decellularized adipose & 5. [5] \\
\hline & tissue and small intestinal submucosa & 6. $[6,37]$ \\
\hline & Synthetic scaffolds: polyanhydride and degradable polyethylene glycols. & 7. [6] \\
\hline Therapeutic scaffolds ${ }^{\S}$ & Collagen / chitosan / glycosaminoglycan & [6] \\
\hline \multirow[t]{4}{*}{ Combination scaffolds } & 1. Injectable composite: beads in a delivery gel & 1. [6] \\
\hline & 2. Gelatin sponges / Polyglycolide mesh / monofilament polypropylene mesh & 2. [6] \\
\hline & 3. Polylactic-co-glycolic acid / polylactic acid & 3. [18] \\
\hline & 4. Synthetic material / collagen / hyaluronic acid & 4. [44] \\
\hline \multirow[t]{4}{*}{ Scaffold-free cell delivery } & Cell-based and cell-aggregated engineered tissues & {$[5,46]$} \\
\hline & 1. Single cells & \\
\hline & 2. Cell sheet & \\
\hline & 3. Microtissues & \\
\hline \multicolumn{3}{|c|}{$\begin{array}{l}\text { †Synthetic scaffolds are easier to fabricate, allow tailoring of the chemical, mechanical (strength and stiffness) and biodegradation properties, permit easier addition of ECM } \\
\text { components and growth factors and have higher uniformity and compatible mechanical and thermal characteristics with biological tissues }[18,28,60,128] \text {. Limitations: they } \\
\text { are generally less biocompatible and may generate immunological responses and cellular toxicity [18]. } \\
\text { ¥Natural scaffolds are more biocompatible and mimic native ECM (i.e. they provide cellular receptor-binding ligands and undergo cell-induced proteolytic degradation } \\
\text { and remodeling) }[18,28,60,128] \text {. Limitations: they require complicated purification process, have poor mechanical, thermal and biodegradation characteristics, may initiate } \\
\text { strong immunological responses and may transmit diseases [18]. } \\
\S \text { Therapeutic scaffolds involve an incorporated therapeutic agent (i.e., a drug or a growth factor) [6]. } \\
\text { ECM: Extracellular matrix. }\end{array}$} \\
\hline
\end{tabular}

would definitely interfere with long-term studies [7]. It is has been observed by researchers and investigators at the University of Texas M.D. Anderson Cancer Center that Yucatan Micro Pigs can be considered as a model animal since they adhere to almost all criteria explained above. Moreover, they are hairless, pliable with a suitable size and a defined growth rate which add extra virtues for them to be utilized [54,55]. However, further characterizations are crucial to reach out the ultimate decision regarding the model animal nomination.

\section{Potential risk of neoplastic behavior}

Oncological safety is often questioned when it comes to utilizing ADSCs for breast restorative techniques and that is because tumor cells are usually following similar pathways to those applied during tissue engineering process (i.e., proliferation, neovascularization and matrix turnover) which may herald neoplastic transformation especially 
in post-malignancy situations [48]. Few in vitro studies betrayed the implication of MSCs in oncological risk potentials [56,57]. However, nothing is proved on clinical context yet [57,58]. Affirming stem cells safety in breast tissue regeneration necessitates more comprehensive and controlled clinical trials [59].

\section{Macro-environment consideration: mechanical \& structural challenges}

There are certain criteria for the designed scaffolds that need to be fulfilled before being considered for breast tissue engineering. Matching the shape of the removed tissue along with providing the essential mechanical support to prevent collapse during the early stage of implantation are one of them and the latter has to be precisely balanced with the rate of degradation [48]. While a complete degradation of the implanted scaffolds accompanied by de novo soft tissue generation is a paramount for breast tissue engineering, it is fundamental to optimize that rate in a manner which ensures adequate maintenance of the spatial structure for the restored volume. Furthermore, it is worthy to monitor the by-products resulting from degradation to see whether they are safe/harmful to the surrounding tissues or may curb the process of tissue regeneration [48].

Evidences of soft tissue formation for both synthetic and natural scaffolds have been reported. A collagen scaffold in particular, has shown a greater cellular attachment and an enhanced lipid accumulation in vitro [60]. Yet it has disappeared completely after its in vivo implantation within 4 weeks due to its rapid degradation rate which may have a nondesirable impact on the sustainability of breast contour and the mechanical support. Similar behavior has been demonstrated for the polylactic acid synthetic scaffolds [61]. In general, it is easier to work with synthetic scaffolds in terms of sustained control over the material properties [62]. However, natural scaffolds tend to be superior with respect to host tissue reaction, soft tissue formation and degradation characteristics [60].

As an endeavor to tackle challenges associated with mechanical and structural aspect, Yuksel $e t$ al., described a complex scaffold design dedicated to match the desired criteria for the engineered breast tissue [48]. The concept of this scaffold is based on a three-layer composition. A thin outer layer, which made of a fibrillar matrix, is designated to withstand the mechanical stress that may result from a material-tissue mismatch besides enhancing 'on-the-shelf availability' via adaptation to volume variation. The second rigid layer is manufactured from a slowly degrading polymer such as polylactic-co-glycolic acid will ensure volume maintenance through providing a structural support which can be further reinforced by a 2-3 mm layer of a honeycomb structure to enhance its strength. This layer accommodates the central highly porous portion which will boost tissue ingrowth [48].

\section{Micro-environment considerations}

Whether synthetic or biological, controlling a scaffold behavior and cell-material interactions is still a real challenge [63]. Biological materials, including collagen and fibrin matrices are recognized by their rich cell signaling domains but most of them are uncharacterized resulting in a poorly regulated cell-scaffold communication [48,64]. Synthetic scaffolds, on the other hand, provide the option of more predictable physical and biological cell-material interactions as well as a better control over structural properties like porosity, density and degradation. However, they are far from resembling the natural external environment with its essential triggering potentials for tissue engineering purposes $[48,65]$.

Several attempts of constructing hybrid scaffolds containing both synthetic and natural components were made to enhance biological interactions such as directing cell migrations and facilitating cell mobility via natural secretion of proteases [66,67]. Another successful example represents the modification of polyethylene glycol (PEG) acrylates with either arginine-glycine-aspartic acid peptide (a cell adhesive peptide) or with heparan sulfate (an ECM component) that were successfully incorporated within scaffolds to promote cellular attachment and allow reservation of heparan-binding growth factors [48]. Matrix modification/governing chemotactic signals are also play a critical role in eliciting inward movement of essential cellular components for breast tissue engineering such as pre-adipocytes and endothelial cells [48]. Such strategies could be embraced for a better control over cell-material interactions.

Cellular exhaustion owing to fibrosis, insufficient blood supply and inappropriate mechanical properties of scaffolds has been observed to impede cellular migration and inhibit translation of the outcomes for larger defects in an in vivo study [48]. Such a challenge can be overcome via delivering matrix degradation enzymes such as plasminogen activator to clear the matrix wall, thence, boosting cellular migration and vascular formation. In theory, distribution of enzymatic activity could be achieved by creating shells of increasing plasminogen activator levels superior to its physiological concentration so that, providing the critical gradient to maximize cell migration [48]. 


\section{Epithelial-mesenchymal transition}

There is increasing research which provide adequate evidence to support the role of epithelial-mesenchymal transition in different stages of cancer and tumor cell progression, invasion and metastasis [68]. While epithelialmesenchymal transition progressing, epithelial cancer cells obtain some molecular changes that facilitate the loss of epithelial features and obtain mesenchymal phenotype. Such alterations encourage cancer cell migration [68]. Additionally, new evidence suggests that epithelial-mesenchymal transition is associated with the increased enrichment of cancer stem-like cells which exhibit mesenchymal characteristics that are resistant to target therapy and chemotherapy [68].

\section{Dormant cancer cells}

Tumor dormancy is an important part of tumor progression process [69]. While, there is major advances in treatment of breast cancer, some factors need to be considered such as tumor heterogeneity as well as mechanisms of resistance which may still affect the standard therapies and make it not effective enough in destroying entire cancer cells, such as dormant cells [69]. However, the biology of breast cancer recurrence should be investigated further to make sure adequate prognosis and therapies obtained [69].

\section{Application of ADSCs in tissue engineering}

For the past few years, ADSCs used as an important cell source and also known as the gold standard for many applications in regenerative medicine [70]. In particular, for breast reconstruction became very interested by clinicians and researchers worldwide because they display great potential for proliferation and differentiation to adipocytes, and obtain acceptable mature adipose graft volume. There are some applications of ADSCs which have more value than others and this will be discussed here. For instance, fat grafting and tissue engineered construct are two main important applications.

\section{Fat grafting}

attracted significant attractions for the past few years and particularly for breast reconstruction autologous fat grafting successfully used by clinicians for various purposes including breast size alteration, filling small-volume defects post-breast-conserving therapy [71,72] and contour defects in implant-based breast reconstructions [73,74]. Overall outcome so far related to fat grafting represent that the larger volume of adipose tissue required to reconstruct the breast mound post-mastectomy is more challenging [75]. According to the literature, autologous fat grafting did not show promising success in breast reconstruction as expected with resorption rates ranging from 25 to $80 \%$ and complications [76]. These limitations consist of oil cyst formation, fat necrosis and calcifications for example latissimus dorsi flap [76] or as a filler for small-volume defects post-breast cancer surgery [77,78]. In 2006, for first time, Matsumoto et al. [79] tried to reduce the rate of resorption (cell-assisted lipo-transfer). This was done through enrichment of autologous lipoaspirates with ADSCs prior to grafting. On the other hand, Kolle et al. [80] showed that residual fat volume of $>80 \%$ in ten patients enriched with ADSCs and compared with controls. The outcome showed that there were higher amounts of adipose tissue, less necrotic tissue and newly formed connective tissue in grafts enriched with ADSCs [81]. These studies are on-going from many researchers world-wide and there is a huge interest as it has shown promising outcome so far.

\section{Breast adipose tissue engineering (in vitro modeling of breast tissue)}

For a better understanding of the breast tissue in terms of structure and function, cellular interactions in morphogenesis and carcinogenesis were evaluated using 2D models, yet revealing unsatisfactory reflection [18,82]. Actually, crucial molecular signals required for tissue-specific architecture and function were lost in these models (i.e., failure to trigger tissue-specific gene expression) [82].

Ultimately, this led to the development of 3D models, which provide a native-like microenvironment that supports cellular attachment and migration and promotes cell-cell and cell-matrix interactions [83]. This enabled the formation of structures that mimic the normal breast tissue [84], which subsequently participated in identifying the essential biochemical and environmental signals for homeostasis and gene expression [82].

Mammary epithelial cells, within these constructs, form polarized organizations of the acinar and ductal structures, which reflects the stromal signals [23]. The significant research efforts of Bissell group resulted in the development of 3D constructs using gel-based scaffolds, like Matrigel, collagen, Matrigel/collagen mix and laminin [18]. 


\begin{tabular}{|c|c|c|c|}
\hline Approach description & Prospective action & Limitations & Ref. \\
\hline $\begin{array}{l}\text { Incorporation of endothelial cells or angiogenetic } \\
\text { factors within the tissue engineered construct or } \\
\text { delivering them to the site of the engineered } \\
\text { tissue }\end{array}$ & $\begin{array}{l}\text { Combats hypoxia, promotes vascularization } \\
\text { through inducing blood vessels formation. }\end{array}$ & $\begin{array}{l}\text { Failure of achieving a long-term sustained effect. } \\
\text { Raising concerns of oncological transformation in } \\
\text { post-cancerous cases while utilizing vascular } \\
\text { promoting factors. }\end{array}$ & {$[6,68]$} \\
\hline Inducing foreign body reaction & $\begin{array}{l}\text { Enhances vascularization and vascular ingrowth } \\
\text { via eliciting host tissue response. Further } \\
\text { degradation of biomaterials may result in } \\
\text { by-products formation, maintaining that response } \\
\text { for defined intervals. }\end{array}$ & $\begin{array}{l}\text { Temporary reaction that will reside after } \\
\text { termination of the response. } \\
\text { Insufficient for large tissue volume. } \\
\text { Slow process. }\end{array}$ & {$[69,70]$} \\
\hline $\begin{array}{l}\text { In vitro or in vivo, pre-vascularization of the } \\
\text { engineered tissue }\end{array}$ & Actively boosts vascularization process. & $\begin{array}{l}\text { Integration of the newly formed vessels with that } \\
\text { of the host is still challenging. }\end{array}$ & [6] \\
\hline Microstamping using nanofluid chambers & $\begin{array}{l}\text { Supports cellular engraftment via establishing an } \\
\text { ex vivo 3D vascular bed in the long-term which } \\
\text { then anastomosed to the host vascular system. }\end{array}$ & $\begin{array}{l}\text { An interesting approach applied in liver tissue } \\
\text { engineering but have not implemented for breast } \\
\text { tissue engineering yet. }\end{array}$ & [71] \\
\hline Utilizing vascularized conduits & $\begin{array}{l}\text { Using a defined vascular pedicle to clinically } \\
\text { vascularize adipose tissue constructs. }\end{array}$ & $\begin{array}{l}\text { Limited, no long-term data are yet available. } \\
\text { The potential ability of pre-existing vascular } \\
\text { pedicle to microsurgically transfer the engineered } \\
\text { construct to a remote site. }\end{array}$ & [7] \\
\hline
\end{tabular}

Mammary epithelial cells seeded into these constructs showed a low proliferation rate, formed polarized growtharrested structures and secreted BM [18].

\section{Scaffolds for breast adipose tissue regeneration}

Selecting the appropriate scaffold for breast tissue regeneration is a crucial factor to promote cell survival [18]. The chemical composition and physical characteristics (microstructural and mechanical features) of the biomaterial govern stem cells behavior and cell-scaffold interactions particularly cellular proliferation, differentiation and adhesion [5,28,85], as this controls cellular responses via providing a biochemical and biophysical environment [5,86]. Moreover, patent microcirculation and ECM are inevitable prerequisites for the survival of the transplanted or regenerated adipose tissue [87].

Ideal biomaterial-derived scaffolds used for breast tissue engineering should have specific features. Basically, the physical, chemical and mechanical characteristics should resemble the normal breast tissue and enable 3D constructs formation that can incorporate cells, growth factors and cellular adhesion functional groups [18]. It should induce the formation of a native-like tissue (functionally and structurally) $[5,28,60]$ and should have cellular affinity, biocompatibility and special immunological properties to interact positively with cellular components $[5,6,18]$. In addition to having in vivo end point, which means being biodegradable, to ensure the integration of the newly formed tissue with the native tissue. Nevertheless, the degradation products should be nontoxic, metabolized and removed from the body $[6,18]$. A salt-leaching method and a computer-controlled knife coater were utilized to make regulated scaffolds, this was then assessed by seeding cells into the 3D scaffold and testing degradability [88]. This method showed that in PLGA and polyglycolic acid scaffolds, which $\mathrm{pH}$ levels decrease over time during degradation, creating an acidic environment for the cells, thus affecting growth [88]. Whereas aliphatic polyesters such as polycaprolactone (PCL), are more easily metabolized and do so via the Krebs cycle in a slow, more controlled manner [88], therefore great consideration should be taken when choosing scaffold biomaterials. On the other hand, balancing structural integrity with scaffold stiffness (flexibility) and constructive remodeling is the key to diminish structural and functional deviation $[5,28]$.

Unlike other tissue engineering applications, the breast, as previously mentioned, has a common chance of developing cancer, making screening a recommended regular procedure, therefore it is vital that the chosen biomaterial does not prohibit or hinder diagnostic imaging [30]. Compared with silicone implants, tissue engineered scaffolds result in lower amounts of scar tissue, and they are also more porous and less radiopaque, thus interfering less with imaging and once the scaffold has degraded interference should be eliminated entirely [30]. Furthermore, a highly porous construct is essential to allow cellular ingrowth and differentiation, tissue integration, angiogenesis, nutrients and wastes exchange and multipotent cells differentiation [6,28]. The most commonly investigated ECM materials used as 3D culture scaffolds for breast tissue regeneration are Matrigel, collagen and its composites, regenerated silk fibroin and polylactic acid [18] (Table 6). 
Sponge scaffolds

Rnjak-Kovacina et al. produced a variety of silk sponges, using an array of silk weight distributions, concentration and crystallinity to achieve a scaffold with properties ideal for tissue engineering [89]. Silk sponges can be produced by methods such as gas foaming, salt leaching and freeze-drying, the application of the sponge determining what technique to carry out [90]. Freeze-drying is simply carried out by freezing a silk solution into a desired shape, the freezing produces crystals which create the porous structure [91]. Freeze-drying can also be carried out using porogens such as sodium chloride, however using just water to create the pores reduces solvent toxicity risks [91]. Rnjak-Kovacina et al. retrieved silk fibroin from Bombyx mori cocoons, removing the protein sericin to get pure silk fibroin for different time periods $(5,10,30$ and $60 \mathrm{~min})$, before placing the silk into lithium bromide to make the silk soluble, at $60^{\circ} \mathrm{C}$ with different times and with different lithium bromide concentrations [89]. Silk fibroin is commonly used as a biomaterial due to its great mechanical properties, controllable degradation capabilities and biocompatibility, giving properties useful to create implants [92]. After solubilizing the silk fibrins, the solution was refined so that the bromine was removed, the concentration of the silk was determined at $6-8 \% \mathrm{wt} / \mathrm{v}$ and was stored at $4^{\circ} \mathrm{C}$ [89]. The solution was then either cast into molds or into wells and frozen at $-20^{\circ} \mathrm{C}$ overnight and then freeze-dried at $-80^{\circ} \mathrm{C}$ for $48 \mathrm{~h}$. The scaffolds were then demolded and annealed in water at different lengths of time or autoclaved, before either using water or phosphate buffered saline to rehydrate the scaffolds [89].

These scaffolds had a variety of different properties due to the different times and molecular weight distributions, but it was shown that scaffold cohesion was improved with increased silk molecular weight, polypeptide content altering degradation rates and silk concentration controlled mechanical properties [89]. This method used human MSCs (hMSCs) from bone marrow aspirate, however could be switched for ADSCs further to test if scaffold properties would suit breast tissue engineering applications.

When deciding on what technique to use to produce a silk sponge scaffold, it should be considered that out of the three mentioned techniques, the freeze-drying technique can have a porosity up to $99 \%$, whereas salt leaching and gas foamed have up to $98 \%$ and $97 \%$, respectively [90]. If compressive strength is an important factor, gas foamed scaffold is the strongest at around $175 \mathrm{KPa}$, as compared with salt leaching and freeze-drying which have compressive strengths of around 280 and $30 \mathrm{KPa}$, respectively [90]. It is also notable, that silk fibroin can be used to make hydrogels, fibers, microspheres and thin films to serve a range of applications [92].

Collagen can also be used to produce sponge scaffolds, although collagen is thought of to be one of the more expensive biomaterials on the market, Lequeux et al. carried out an analysis of porcine autologous ADSCs seeded onto a collagen scaffold [93]. These scaffolds were cultured for 10 days prior to subcutaneous implantation, into the porcine and analyzed over a period [93]. This resulted in vascularized connective tissue with improved extracellular matrix around the ADSCs, Lequeux et al. reporting that this combination of collagen scaffold with ADSCs served as a good solution for repairing soft tissue, due to increasing the thickness of the skin, removing the problems commonly associated with fat grafting [93]. Collagen sponges have been compared against esterified hyaluronic acid and other sponge, these scaffolds were seeded and cultured in vitro with preadipocytes, then implanted into nude mice [94]. Differentiation occurred the earliest in the hyaluronic scaffolds, showing more ECM than the other two scaffold types and had a larger number of cells present than the other woven and nonwoven scaffolds [94]. Furthermore, showing that collagen and hyaluronic acid can be used as scaffolds, but produce different results, the importance of choosing a suitable scaffold highlighted here as biomaterials can be modified to make large changes.

Hong et al. combined a gelatin sponge scaffold with human ADSCs, to analyze the differentiation and proliferation of these cells on a soft scaffold in vivo [12]. After implementing a medium to encourag0e adipogenicity, this seeded scaffold was implanted into the backs of mice and within 4 weeks fat had formed from adipogenic cells [12]. This method and combination of gelatin scaffold with human ADSCs could be used to encourage fat growth, using stem cells derived autologously to prevent immunological responses, with gelatin being an easily sourced biomaterial as a scaffold choice.

Sponge scaffolds can create porous, soft and inexpensive constructs for ADSCs growth and differentiation, potentially suitable for human breast reconstruction if caution and care is taken throughout the entire procedure.

\section{Additive manufactured scaffolds}

Lipofilling and tissue engineering can be combined together, creating a bespoke scaffold for each patient, allowing cells to proliferate within the breast before lipofilling [30]. Where lipofilling has little to no mechanical strength and structure of it cannot be controlled, a biodegrading scaffold would allow for a chosen shape and size supporting the 
growth of new cells. Chhaya et al. evaluated this combination of scaffold and lipofilling, by implanting an empty scaffold, a scaffold containing lipoaspirate and an empty scaffold which had lipoaspirate injected, after a 2 week prevascularization period, into minipigs [95]. Additive manufacturing was performed to create scaffolds from PCL, but first liposuction had to take place in order to harvest lipoaspirate. Then these scaffolds were subglandularly implanted into immunocompetent minipigs for 24 weeks [95]. The results from this experiment showed that the combination of a scaffold with a delayed lipofilling, was the most successful histologically and has the most similarities to natural breast tissue, containing approximately $47 \%$ of adipose tissue [95].

Bespoke patient scaffolds have been produced, by scanning the patients' breast, then additive manufacturing was carried out using polyD-L-lactide polymer as the biomaterial, in a process called fused deposition modeling [96]. Fused deposition modeling requires no solvents to be used alongside the aliphatic polyesters and has constant flow as heating time is reduced, making the modeling easier to carry out compared with solid freeform fabrication or 3D printing [97].

Prior to seeding these scaffolds, human umbilical cord perivascular cells were cultured in vitro for 6 weeks, human umbilical vein was also seeded into the scaffold, then this was then implanted subcutaneously into nude rodents [96]. These bespoke-made polymer scaffolds after 24 weeks had an increase of adipose tissue in the area of $81.2 \%$, tissue was also well vascularized, Chhaya et al. showing that these $3 \mathrm{D}$ additive manufactured methods are suitable constructs for increasing adipose tissue within the breast [96].

Custom 3D scaffold production reduces surgery complexity, where a surgeon might have been required to shape silicone implants to suit a patient or use a variety of tissue flaps together to produce a natively similar aesthetic breast, additive manufacturing makes the procedure more straight forward [30], using scanning methods to copy the desired shape accurately [96].

\section{Gel scaffolds}

An alternative to 3D structures for scaffolding, could be using gels such as hydrogels instead, which are polymeric structures that swell when introduced to water $[12,98]$. These gels do not provide as much structural support or mechanical strength, but can be injected into tissue and do not necessarily require surgery to implant. Wittmann et al. demonstrated the usefulness of fibrin hydrogels, retrieving stromal-vascular fraction cells and combing these with the hydrogels to form adipose tissue in vivo in nude mice [99]. These cells were cultured for 1 week prior to in vivo implantation, after 4 weeks after histological and histomorphic evaluation, finding vascular structures and mature adipocytes throughout the formed area [99].

Hydrogels can be produced from many polymers to allow soft tissue formation, a few examples include: PEG [100], myogels [101], collagen [102] and hyaluronic acid [102].

Natural hydrogels may seem superior to synthetic hydrogels, because of their biodegradability and biocompatibility capabilities, unfortunately despite that natural hydrogels commonly cause inflammatory reactions and are not able to mechanical maintain the structure [98]. Synthetic hydrogels can be custom-made to improve strength, biodegradability but there is still ongoing research on finding a way to synthetically represent the ECM and bioactive molecules might need to be incorporated to encourage cell adhesion and migration [98].

PEG can be altered to slow or prevent degradation of the hydrogel, this can be done by introducing branches or cross-linking of peptides and other structures [100]. Nondegrading hydrogels made from PEG have shown to be less successful than enzymatically degradable hydrogels, in which enzymatically degradable hydrogels encourage adipose-tissue like formation more thoroughly [100]. However, it should be noted that enzymatic degradation of these degradable PEG hydrogels can occur in as little as within 10 days [100], which might not be long enough to support the growing tissue structures.

To produce a hydrogel firstly, a combination of desired monomers needs to be collected with inhibitors, initiators and cross-linking agents, this is then polymerized prior to preparing the hydrogel [103]. This is then separated and washed, before drying and sizing [103]. Anything that is excess material can be repolymerized via recycling and used again. After sizing additive inclusion can happen and post reaction may occur, once complete the hydrogel can then be used or packaged appropriately [103]. It should be noted that this is only a vague overview of hydrogel production, the timings, temperatures and quantities will vary depending on properties needed from the hydrogel.

Myogels have been used as scaffolds for adipose tissue support, as an alternative to matrigel scaffolds [101]. Myogels can be prepared from extracting extracellular matrices from skeletal muscle, made up of laminin and collagen, Abberton et al. have shown this to be viable alternative, with similar discrepancies in growth factors to 
balance out their worth [101]. When used in vivo in rats, adipose tissue formed sufficiently along with vascularized endothelium, an encouraging result to prevent cell necrosis [101].

Matrigel scaffolds alone have proved unsuccessful to meet the mechanical property requirements of the breast ECM, yet in combination with collagen type one, the scaffolds have been shown to allow formation of ductal and alveolar structures [104].

Microbeads can be used alongside hydrogels, microbeads can be used to increase porosity and allow morphological control [103]. This can be done by using a phase including aqueous solution, cross-linking agents and monomers with a dispersing agent and nonsolvent all combined [103]. Once stirred the initiator can be added to conduct gelation of the mixture, and similar to the normal hydrogel process is separated and washed before drying, then the hydrogel beads are formed [103].

Importantly, hydrogels have many flaws that could impede on the design of a tissue engineered scaffold for soft tissue. Mimicking of the ECM is a critical component of a scaffold in ensuring cell survival, alongside controlling the expansion of these hydrogels to limit molecular diffusion [98,105].

\section{Electrospun scaffolds}

Electrospinning is a commonly technique used for tissue engineering various scaffolds [106,107], however this is usually in applications where cancer has not been an issue, as scaffold ECM could encourage the growth of potentially malignant cells [108]. Electrospun scaffolds made from fibers can increase adipose tissue growth and adhesion more so than collagen, while also being shown to act as an immunosuppressant, when using polymers polydioxanone, polyglycolic acid, polylactic acid, and PCL $[108,109]$.

Electrospinning has been used to model the shape, structure and environment of the breast in a 3D manner in vitro, allowing a closely related environment to the native breast rather than using $2 \mathrm{D}$ structures [18]. $2 \mathrm{D}$ structures having poorer cell proliferation and effective arrangement when compared with $3 \mathrm{D}$ structures, with the use of ADSCs [110]. Nanofiber scaffolds can be produced to represent tissue fibers found in the breast ECM, encouraging cell adhesion and biocompatibility, producing closely related $3 \mathrm{D}$ surroundings for scientists to test and explore how breast cancer develops, this teaching how the cancer in the breast spreads working towards alternative treatments or therapies [18].

Collagen fibers can sometimes proliferate and spread in the place of removed tissue during mastectomies, therefore the texture and feel of this tissue can feel abnormal causing discomfort or looking unsightly to the patient [111]. Methods to increase adipose tissue in the place of collagen, becoming more important in the success of developing a realistic tissue [111]. Where biopolymers, ECM structures and other native tissue structures need to be implemented to provide the most natural tissue possible [108].

Electrospun scaffolds can be used to fill spaces, where the cancerous breast tissue has been removed from, as an alternative to pedicled flap procedures [112], as previously mentioned fat transfer can result in tissue loose because of necrosis. This has been shown to work better, increasing tissue area compared with fat transfer, allowing larger breast volumes to be reconstructed, proving improvement with pore size increase to allow greater cell migration [112].

There are a multitude of ways electrospinning can be carried out, parameters can be altered where deemed appropriate in order to obtain a scaffold with different properties.

In this experiment carried out by Sana et al., creating scaffolds with both aligned and nonaligned fibers, of particular interest finding that radial alignment of collagen with tumors increased the invasion and metastasis of tumors [108]. This method being shown to be useful for studying breast carcinoma development, which can be modified to provide a 3D ECM model structure as closely similar to the native breast ECM as possible [108].

Scaffolds made via electrospinning can also be mixed with minced adipose tissues, slow-degrading scaffold materials prevent the structure from failing as the cells proliferate and fill the site of the scaffold, with the inclusion of endothelial cells being shown to advance adipose tissue proliferation [110]. Development of Electrospun scaffolds still requires improvement, with these scaffolds having pores too small in size to allow sufficient cell seeding, larger pore size resulting in poorer mechanical properties, hence potential for scaffolds produced from more than one technique to eliminate disadvantages $[109,113]$.

\section{Clinical use in patients with breast cancer}

As described above, ADSCs has great properties and advantages toward patients with breast cancer and augmentation issues such as pro-survival, anti-apoptotic effects, pro-angiogenic [114], immunosuppression, immunemodulatory [115], tissue growth, and cellular homing are dysregulated in tumor progression and metastasis [114,116]. 
However, this is an important and fast-growing field and many researchers are very optimistic about the bright future of breast tissue reconstruction using ADSCs.

\section{Conclusion}

Although, many breast reconstructive techniques have been utilized for post-mastectomy patients the goal of an optimal stratification and achieving complication-free outcomes has not been reached yet. In light of that fact, breast tissue engineering field employing ADSCs, in particular, has been scouted and this may open up great avenues toward combating those obstacles in addition to paving the way for more desirable results in terms of patient satisfaction and psychological improvement. However, further elucidations are needed to unveil many questioned aspects in this realm like oncological safety for instance, and that necessitates well-structured randomized control trials to accomplish the demanded 'from benchside to bedside' translation.

\section{Future perspective}

Few studies have been carried out on human patients involving breast tissue engineering, this is due to a range of physiological reasons and risks involved, that could make a person's life very uncomfortable or even increase the chance of breast cancer reoccurring. Although many basic problems require addressing, such as volume of adipose tissue, preventing malignancy growth within the tissue or reducing rejection rates before human trials increase, breast tissue engineering can be improved a great deal more.

With breast development occurring most drastically through puberty and pregnancy [18], it is important to consider that breast cancer could, although less commonly, appear at a young age in women. Women developing breast cancer before having children, may still desire to have children one day if cancer is ridden of completely and chances of reoccurrence are low, it is recommended that oncologists give advice on safety for the female, along with waiting for a year for all radiation damage to have been removed from the body [117]. If a female does wish to have a child, she may also wish to breast feed her child, this could be due to research showing that breast milk can benefit growing children in ways such as development of organs, hair and nail growth, gut bacteria health and reduced pathogen exposure [118]. This literature talks mainly about ADSCs for fat growth within the breast, but if ducts and glands are required for the production of milk, other cells would need to be mixed specifically to allow a mother to lactate, in response to pregnancy hormone stimulation [18]. This advancement would prove difficult due to little understanding of the ECM signals involved in mammary gland acinus lactation [22]. Swamydas et al. successfully have developed breast-like acini and ducts using a combination of Matrigel, collagen and agarose, in 3D culture environments [84]. Which with improvement could lead to a structure and architecture closely related to the human native acini [84].

Nipple-areola complex reconstruction may also be required, to deliver the milk to the child. And even more commonly, females might wish to preserve the areola for self-confidence purposes or otherwise. Reconstruction of the nipple-areola complex could involve reattachment of the native nipple to vascular supplies, but some females may lose their areolas due to cancer growth, therefore tissue engineering of the nipple-areola complex would also be required [30].

However, safety may be again a factor here again as the child could be drinking milk from an unhealthy source, which could adversely affect the child when they grow up. Some females, on the other hand, would not want to breastfeed due to pain or other concerns they may have.

Chemotherapy is used in the treatment of cancer within the breast, despite this however, cancer can return to a patient after remission. Therefore, other methods to prevent cancer returning, are highly sought after, to encourage and to reassure the patient, rather than they fear having to go through the distress of cancer procedures again. Antitumor biomaterials and drug delivery systems are growing more and more popular in cancer research.

Chemotherapy has many side effects and limitations, of which discourages some patients to carry out the procedure as they fear the aftermath. Some side effects can include risk of infection or bleeding (from reduced blood cells), hair loss, sickness and peripheral neuropathy [119], however there are many more adverse effects that are undesirable. Nanoparticle drug delivery systems can be used to target cancer cells and act similarly to chemotherapy, when drugs are held within these systems and coated with a material (such as PEG to allow distant travelling to target cells), these drug-delivery-systems can be of benefit to a patient by using ligands to destroy malignant cells [120].

Fan et al. formed a drug-delivery-system that was able to target tumor cells, allowing drug release using $\mathrm{SiO}_{2}$ AuNP-based nanoparticles at the target site experimenting in vivo, reducing the tumor size to $0.0025 \%$ of its original size, decreasing systemic toxicity and acting as an antitumor [120]. These systems can be improved 
and tested in environments more closely related to native breast tissue rather than in vivo, to give a clearer result of the safety and implications there may be of using these drug systems in a human body within different sorts of cells [120].

Due to the adaptability of electrospinning techniques, to produce scaffolds for tissue engineering, not only can these electrospun scaffolds be used for tissue growth directing and acting as local ECM, but they can also be used to deliver drugs to specific locations in the body [121]. This could be utilized to directly disperse a cancer therapy drug at a required location, where the addition of drugs to the scaffold can be done simply, the large surface area involved improving drug release control [121]. However, although processes similar to drug delivery and encapsulation have been trialed using coaxial electrospinning with a variety of polymers $[122,123]$ there are still many problems concerning effective drug delivery. Drug release can be premature [121] therefore not reaching the target site, however hydrophobic polymers are being explored as a solution to this, alongside the angle of the fibers to control the release more strictly [113]. Alongside this issue, the drug itself must not be affected during production of the delivery structure, as conditions such as temperature or voltage, may alter the effectivity or performance of the drug [121]. Thus, research has been going into fiber production which affects the drug minimally, as such studies as demonstrated by Mickova et al., showing how coaxial electrospinning allows enzymes to be held inside of polymer PVA core with PCL shell to be obtained, holding back early enzymatic activation [122]. Hence, techniques like these can be carried forward to slow drug release through the carrier structure where required. Also, when the content of drug within the structures is increased, it has been seen to worsen the mechanical properties [124]. Throughout, the major benefit of targeted drug delivery through tissue engineered scaffolds, hoping to minimize the area effected by the drug and hence reducing the side effects of procedures such as chemotherapy.

Another method to reduce mortality associated with the reoccurrence potential of breast cancer, could involve malignant growth detection via chemicals within the scaffolds. Research has been growing in the area of exploring how MSCs home from afar and travel towards breast tumors, using this to trigger a warning preventing hidden growth of malignant cells [125]. This is due to tumor cell-specific receptors present on surfaces, tumor-derived factors and many other influences from MSCs [125]. In vivo studies by Khakoo et al., have shown that human MSCs can be used to slow or stop tumor growth of Kaposi's sarcoma as well as homing to malignant areas [126]. MSCs can be administered to the body through intravenous drips, however this can get stuck where not required so not all reach the target site [125], therefore a method of releasing the MSCs slowly from the scaffold, perhaps at the same time as degradation would be beneficial in allowing the MSCs to quickly reach the homed tissue. These MSCs can be tracked to find potential tumor activity using methods such as magnetic resonance imaging or computed tomography, with various advantages and disadvantages associated with these methods [125].

Scaling up scaffolds for tissue engineering breast for reconstruction, is another problem, with current methods focusing on very small production batches. A method to industrialize and mass produce tissue engineered breast tissue, for the bespoke requirement of the patients may be complicated, but a line production technique may be necessary in order to keep up with the quantities of people needing breast reconstruction involving tissue engineering processes.

Few future directions of breast tissue engineering have been discussed here, with many more possible upgrades to these processes and outcomes for patients, but with continued research and study these visions will become true. Overall, the future of breast tissue engineering can advance immensely, and once the breast is understood completely at a cellular level and can be replicated closely, the repercussions of breast surgery can be near to eradicated. In turn, improving the lives of breast cancer patients.

\section{Financial \& competing interests disclosure}

The authors have no relevant affiliations or financial involvement with any organization or entity with a financial interest in or financial conflict with the subject matter or materials discussed in the manuscript. This includes employment, consultancies, honoraria, stock ownership or options, expert testimony, grants or patents received or pending, or royalties.

No writing assistance was utilized in the production of this manuscript.

Open access

This work is licensed under the Creative Commons Attribution 4.0 License. To view a copy of this license, visit visit http://creativecommons.org/licenses/by/4.0/ 
Breast anatomy, histology \& development

- Breast anatomy, histology and development discussed.

Epithelial cells interactions with extracellular matrix proteins

- Epithelial cells survival, proliferation, differentiation, polarity and invasive capacity are governed by cell-cell and cell-microenvironment interactions.

Biomechanical properties of breast tissue

- The mechanical properties of the soft tissues involve a sophisticated combination of elasticity and viscosity that governs tissue deformation.

Current clinical practices for breast reconstruction

- There are two factors determining the type and timing of the reconstructive procedure, patient's general health status and then patient's preference.

- Implant-based reconstruction: associated with several complications that may lead to implant failure.

- Autologous flap reconstruction: more complex with longer recovery and are associated with potential donor and recipient-site morbidity.

Challenges facing adipose tissue engineering for breast regeneration

- Breast adipose tissue engineering: enabled the formation of structures that mimic the normal breast tissue.

- Scaffolds for breast adipose tissue regeneration: The most commonly investigated extracellular matrix materials used as 3D culture scaffolds for breast tissue regeneration are Matrigel, collagen and its composites, regenerated silk fibroin and polylactic acid.

Scaffolds for scaffolds for breast tissue regeneration

- Additive manufactured scaffolds: additive manufacturing was performed to create scaffolds from polycaprolactone, but firstly liposuction had to take place in order to harvest lipoaspirate.

- Gel scaffolds: an alternative to 3D structures for scaffolding, could be using gels such as hydrogels instead, which are polymeric structures that swell when introduced to water.

- Electrospun scaffolds: electrospun scaffolds made from fibers can increase adipose tissue growth and adhesion more so than collagen, while also being shown to act as an immunosuppressant.

Adipose tissue-derived stem cells

- Adipose tissue-derived stem cells (ADSCs): ADSCs prevent severe graft-versus-host disease in vitro and in vivo and to be genetically stable in long-term culture and therefore they have great potential applications for the repair and regeneration of acutely and chronically-damaged tissues.

- Cell survival and vascularization: ensuring adequate nutrition and oxygenation have been recognized as a critical challenge in tissue engineering field in general and breast tissue engineering.

- Volume-skin coverage coordination: utilizing tissue engineering modalities allow an opportunity of predetermining the desired shape and size of the restored breast by determining the scaffold shape and cell numbers.

Application of ADSCs in tissue engineering

- ADSCs used as an important cell source and also known as the gold standard for many applications in regenerative medicine.

Clinical use in patients with breast cancer

- ADSCs has great properties and advantages toward patients with breast cancer and augmentation issues such as pro-survival, anti-apoptotic effects, pro-angiogenic, immunosuppression, immune-modulatory, tissue growth and cellular homing are dysregulated in tumor progression and metastasis.

\section{References}

1. Coughlin SS, Ekwueme DU. Breast cancer as a global health concern. Cancer Epidemiol. 33(5), 315-318 (2009).

2. Bray F, Ferlay J, Soerjomataram I, Siegel RL, Torre LA, Jemal A. Global cancer statistics 2018: GLOBOCAN estimates of incidence and mortality worldwide for 36 cancers in 185 countries. CA Cancer J. Clin. 68(6), 394-424 (2018).

3. Jeevan R, Cromwell DA, Browne JP et al. Findings of a national comparative audit of mastectomy and breast reconstruction surgery in England. J. Plas. Recon. Aesthet. Surg. 67(10), 1333-1344 (2014).

4. NICE. Early and locally advanced breast cancer: diagnosis and treatment NICE Guideline NICE www.nice.org.uk/guidance/ng101 (2018).

5. Combellack EJ, Jessop ZM, Naderi N et al. Adipose regeneration and implications for breast reconstruction: update and the future. Gland Surg. 5(2), 227 (2016).

6. Burg KJ, Inskeep B, Burg TC. Breast tissue engineering: reconstruction implants and three-dimensional tissue test systems. In: Principles of Tissue Engineering (Eds). Elsevier, USA, 727-749 (2014). 
7. Patrick CW Jr. Breast tissue engineering. Annu. Rev. Biomed. Eng. 6, 109-130 (2004).

8. Wyld L, Audisio RA, Poston GJ. The evolution of cancer surgery and future perspectives. Nat. Rev. Clin. Oncol. 12(2), 115 (2015).

9. Kim E-H, Heo CY. Current applications of adipose-derived stem cells and their future perspectives. World J. Stem Cells 6(1), 65 (2014).

10. Naderi N, Combellack EJ, Griffin M et al. The regenerative role of adipose-derived stem cells (ADSC) in plastic and reconstructive surgery. Int. Wound J. 14(1), 112-124 (2017).

11. Kern S, Eichler H, Stoeve J, Klüter H, Bieback K. Comparative analysis of mesenchymal stem cells from bone marrow, umbilical cord blood, or adipose tissue. Stem Cells 24(5), 1294-1301 (2006).

12. Hong L, Peptan IA, Colpan A, Daw JL. Adipose tissue engineering by human adipose-derived stromal cells. Cells Tissues Organs 183(3), 133-140 (2006).

13. Lanigan F, O'connor D, Martin F, Gallagher W. Common molecular mechanisms of mammary gland development and breast cancer. Cell. Mol. Life Sci. 64(24), 3159-3184 (2007).

14. Hassiotou F, Geddes D. Anatomy of the human mammary gland: current status of knowledge. Clin. Anat. 26(1), 29-48 (2013).

15. Ramião NG, Martins PS, Rynkevic R, Fernandes AA, Barroso M, Santos DC. Biomechanical properties of breast tissue, a state-of-the-art review. Biomech. Model. Mechanobiol. 15(5), 1307-1323 (2016).

16. Gefen A, Dilmoney B. Mechanics of the normal woman's breast. Tech. Health Care 15(4), 259-271 (2007).

17. Golatkar A, Anand D, Sethi A. Classification of breast cancer histology using deep learning. Presented at: International Conference Image Analysis and Recognition. (2018).

18. Maghdouri-White Y, Bowlin GL, Lemmon CA, Dreau D. Bioengineered silk scaffolds in 3D tissue modeling with focus on mammary tissues. Mat. Sci. Eng. C 59, 1168-1180 (2016).

19. Schwimmer R, Ojakian GK. The alpha 2 beta 1 integrin regulates collagen-mediated MDCK epithelial membrane remodeling and tubule formation. J. Cell Sci. 108(6), 2487-2498 (1995).

20. Martin SS, Leder P. Human MCF10A mammary epithelial cells undergo apoptosis following actin depolymerization that is independent of attachment and rescued by Bcl-2. Mol. Cell. Biol. 21(19), 6529-6536 (2001).

21. Weaver VM, Lelièvre $S$, Lakins JN et al. $\beta 4$ integrin-dependent formation of polarized three-dimensional architecture confers resistance to apoptosis in normal and malignant mammary epithelium. Cancer Cell 2(3), 205-216 (2002).

22. Nelson CM, Bissell MJ. Modeling dynamic reciprocity: engineering three-dimensional culture models of breast architecture, function, and neoplastic transformation. Presented at: Seminars in cancer biology. 15(5) 342-352 (2005).

23. Lance A, Yang CC, Swamydas M et al. Increased extracellular matrix density decreases MCF10A breast cell acinus formation in 3D culture conditions. J. Tissue Eng. Regen. Med. 10(1), 71-80 (2016).

24. Lopez J, Mouw J, Weaver V. Biomechanical regulation of cell orientation and fate. Oncogene 27(55), 69-81 (2008).

25. Rzymski P, Skórzewska A, Skibińska-Zielińska M, Opala T. Factors influencing breast elasticity measured by the ultrasound Shear Wave elastography-preliminary results. Arch. Med. Sci. 7(1), 127 (2011).

26. Malata C, Mcintosh S, Purushotham A. Immediate breast reconstruction after mastectomy for cancer. Brit. J. Surg. 87(11), 1455-1472 (2000).

27. Coleman SR, Saboeiro AP. Fat grafting to the breast revisited: safety and efficacy. Plas. Reconstruct. Surg. 119(3), 775-785 (2007).

28. O'halloran N, Courtney D, Kerin MJ, Lowery AJ. Adipose-derived stem cells in novel approaches to breast reconstruction: their suitability for tissue engineering and oncological safety. Breast Cancer Basic Clin. Res. 11, DOI: 10.1177/1178223417726777 1-18 (2017).

29. Leff DR, Bottle A, Mayer E et al. Trends in immediate postmastectomy breast reconstruction in the United Kingdom. Plas. Reconstruct. Surg. Global Open 3(9), e507 (2015).

30. Visscher LE, Cheng M, Chhaya M et al. Breast augmentation and reconstruction from a regenerative medicine point of view: state of the art and future perspectives. Tiss. Eng. Part B Rev. 23(3), 281-293 (2017).

31. Brown SL, Todd JF, Luu H-MD. Breast implant adverse events during mammography: reports to the Food and Drug Administration. J. Womens Health 13(4), 371-378 (2004).

32. Tang SS, Gui GP. A review of the oncologic and surgical management of breast cancer in the augmented breast: diagnostic, surgical and surveillance challenges. Ann. Surg. Oncol. 18(8), 2173-2181 (2011).

33. Nahabedian MY, Patel K. Autologous flap breast reconstruction: surgical algorithm and patient selection. J. Surg. Oncol. 113(8), 865-874 (2016).

34. Sundaramurthy S, Suresh H, Anirudh A, Rozario AP. Primary lumbar hernia: a rarely encountered hernia. Int. J. Surg. Case Rep. 20, 53-56 (2016).

35. Thorne C, Chung K, Goasain A. Grabb and Smith's Plastic Surgery. Wolters Kluwer Health Adis (ESP) 7 (2013).

36. Rosen ED, Spiegelman BM. What we talk about when we talk about fat. Cell 156(1-2), 20-44 (2014). 
37. Caplan AI. Mesenchymal stem cells: time to change the name! Stem Cells Transl. Med. 6(6), 1445-1451 (2017).

38. Brooks A, Futrega K, Liang X et al. Concise review: quantitative detection and modeling the in vivo kinetics of therapeutic mesenchymal stem/stromal cells. Stem Cells Transl. Med. 7(1), 78-86 (2018).

39. Collins E, Gu F, Qi M et al. Differential efficacy of human mesenchymal stem cells based on source of origin. J. Immunol. 193(9), 4381-4390 (2014).

40. Corcione A, Benvenuto F, Ferretti E et al. Human mesenchymal stem cells modulate B-cell functions. Blood 107(1), 367-372 (2006).

41. Donnenberg VS, Zimmerlin L, Rubin JP, Donnenberg AD. Regenerative therapy after cancer: what are the risks? Tissue Eng. Part B Rev. 16(6), 567-575 (2010).

42. Bunnell BA, Flaat M, Gagliardi C, Patel B, Ripoll C. Adipose-derived stem cells: isolation, expansion and differentiation. Methods 45(2), 115-120 (2008).

43. Assis-Ribas T, Forni MF, Winnischofer SMB, Sogayar MC, Trombetta-Lima M. Extracellular matrix dynamics during mesenchymal stem cells differentiation. Dev. Biol. 437(2), 63-74 (2018).

44. Mortada I, Mortada R. Epigenetic changes in mesenchymal stem cells differentiation. Eur. J. Med. Genet. 61(2), 114-118 (2018).

45. Scott MA, Nguyen VT, Levi B, James AW. Current methods of adipogenic differentiation of mesenchymal stem cells. Stem Cells Develop. 20(10), 1793-1804 (2011).

46. Ullah I, Subbarao RB, Rho GJ. Human mesenchymal stem cells-current trends and future prospective. Biosci. Rep. 35(2), e00191 (2015).

47. Docheva D, Haasters F, Schieker M. Mesenchymal stem cells and their cell surface receptors. Curr. Rheumatol. Rev. 4(3), 155-160 (2008).

48. Yuksel E, Choo J, Wettergreen M, Liebschner M. Challenges in soft tissue engineering. Presented at: Seminars in plastic surgery. 19(3), 261-270 (2005).

49. Hutley LJ, Herington AC, Shurety W et al. Human adipose tissue endothelial cells promote preadipocyte proliferation. Am. J. Physiol. Endocrinol. Metab. 281(5), E1037-E1044 (2001).

50. Sierra-Honigmann MRO, Nath AK, Murakami C et al. Biological action of leptin as an angiogenic factor. Science 281(5383), 1683-1686 (1998).

51. Zhang Q-X, Magovern CJ, Mack CA, Budenbender KT, Ko W, Rosengart TK. Vascular endothelial growth factor is the major angiogenic factor in omentum: mechanism of the omentum-mediated angiogenesis. J. Surg. Res. 67(2), 147-154 (1997).

52. Findlay MW, Dolderer JH, Trost $\mathrm{N}$ et al. Tissue-engineered breast reconstruction: bridging the gap toward large-volume tissue engineering in humans. Plas. Reconstruct. Surg. 128(6), 1206-1215 (2011).

53. Yuan Y, Ogawa R. Tissue-engineered breast reconstruction: bridging the gap toward large-volume tissue engineering in humans. Plas. Reconstruct. Surg. 135(1), 236e-237e (2015).

54. Rowson AR, Daniels KM, Ellis SE, Hovey RC. Growth and development of the mammary glands of livestock: a veritable barnyard of opportunities. Presented at: Seminars in cell \& developmental biology. (23(5), 557-566 (2012).

55. Lavker RM, Dong G, Zheng P, Murphy GF. Hairless micropig skin. A novel model for studies of cutaneous biology. Am. J. Pathol. 138(3), 687 (1991).

56. Kucerova L, Skolekova S, Matuskova M, Bohac M, Kozovska Z. Altered features and increased chemosensitivity of human breast cancer cells mediated by adipose tissue-derived mesenchymal stromal cells. BMC Cancer 13(1), 535 (2013).

57. Mestak O, Hromadkova V, Fajfrova M, Molitor M, Mestak J. Evaluation of oncological safety of fat grafting after breast-conserving therapy: a prospective study. Ann. Surg. Oncol. 23(3), 776-781 (2016).

58. Lohsiriwat V, Curigliano G, Rietjens M, Goldhirsch A, Petit JY. Autologous fat transplantation in patients with breast cancer:"silencing" or "fueling" cancer recurrence? Breast 20(4), 351-357 (2011).

59. Boháč M, Csöbönyeiová M, Kupcová I, Zamborský R, Fedeleš J, Koller J. Stem cell regenerative potential for plastic and reconstructive surgery. Cell Tissue Banking 17(4), 735-744 (2016).

60. Choi JH, Gimble JM, Lee K et al. Adipose tissue engineering for soft tissue regeneration. Tiss. Eng. Part B Rev. 16(4), 413-426 (2010).

61. Mauney JR, Nguyen T, Gillen K, Kirker-Head C, Gimble JM, Kaplan DL. Engineering adipose-like tissue in vitro and in vivo utilizing human bone marrow and adipose-derived mesenchymal stem cells with silk fibroin 3D scaffolds. Biomaterials 28(35), 5280-5290 (2007).

62. Lavik E, Langer R. Tissue engineering: current state and perspectives. App. Microbiol. Biotech. 65(1), 1-8 (2004).

63. Arabpour Z, Youseffi M, Soon CF et al. Designing biomaterials for regenerative medicine:state-of-the-art and future perspectives, Tissue Engineering Strategies for Organ Regeneration. Regen. Med. CRC Press, 1 DOI:10.4324/9780429422652-1 (2020).

64. Gentile P, Mccolgan-Bannon K, Gianone NC, Sefat F, Dalgarno K, Ferreira AM. Biosynthetic PCL-graft-collagen bulk material for tissue engineering applications. Materials 10(7), 693 (2017).

65. Deshpande P, Ramachandran C, Sefat F et al. Simplifying corneal surface regeneration using a biodegradable synthetic membrane and limbal tissue explants. Biomaterials 34(21), 5088-5106 (2013).

66. Hubbell JA. Biomaterials in tissue engineering. Biotechnology 13(6), 565 (1995). 
67. Luo Y, Shoichet MS. A photolabile hydrogel for guided three-dimensional cell growth and migration. Nat. Mater. 3(4), 249 (2004).

68. Wu Y, Sarkissyan M, Vadgama JV. Epithelial-mesenchymal transition and breast cancer. J. Clin. Med. 5 (2), 13 (2016).

69. Gelao L, Criscitiello C, Fumagalli L et al. Tumour dormancy and clinical implications in breast cancer. Ecancermedicalscience 7(320), 10.3332/ecancer.2013.320 (2013).

70. Mizuno H, Tobita M, Uysal AC. Concise review: adipose-derived stem cells as a novel tool for future regenerative medicine. Stem Cells 30(5), 804-810 (2012).

71. Illouz YG, Sterodimas A. Autologous fat transplantation to the breast: a personal technique with 25 years of experience. Aesthetic Plas. Surg. 33(5), 706-715 (2009).

72. Zheng D-N, Li Q-F, Lei $\mathrm{H}$ et al. Autologous fat grafting to the breast for cosmetic enhancement: experience in 66 patients with long-term follow up. J. Plas. Recon. Aesthet. Surg. 61(7), 792-798 (2008).

73. Serra-Renom JM, Muñoz-Olmo JL, Serra-Mestre JM. Fat grafting in postmastectomy breast reconstruction with expanders and prostheses in patients who have received radiotherapy: formation of new subcutaneous tissue. Plas. Reconstruct. Surg. 125(1), 12-18 (2010).

74. Salgarello M, Visconti G, Barone-Adesi L. Fat grafting and breast reconstruction with implant: another option for irradiated breast cancer patients. Plas. Reconstruct. Surg. 129(2), 317-329 (2012).

75. Agha RA, Goodacre T, Orgill DP. Use of autologous fat grafting for reconstruction postmastectomy and breast conserving surgery: a systematic review protocol. BMJ Open 3(10), (2013).

76. Sinna R, Delay E, Garson S, Delaporte T, Toussoun G. Breast fat grafting (lipomodelling) after extended latissimus dorsi flap breast reconstruction: a preliminary report of 200 consecutive cases. J. Plas. Recon. Aesthet. Surg. 63(11), 1769-1777 (2010).

77. Delay E, Garson S, Tousson G, Sinna R. Fat injection to the breast: technique, results, and indications based on 880 procedures over 10 years. Aesthetic Surg. J. 29(5), 360-376 (2009).

78. Khouri R, Del Vecchio D. Breast reconstruction and augmentation using pre-expansion and autologous fat transplantation. Clinics Plas. Surg. 36(2), 269-280 (2009).

79. Matsumoto D, Sato K, Gonda K et al. Cell-assisted lipotransfer: supportive use of human adipose-derived cells for soft tissue augmentation with lipoinjection. Tissue Eng. 12(12), 3375-3382 (2006).

80. Bielli A, Scioli MG, Gentile P et al. Adult adipose-derived stem cells and breast cancer: a controversial relationship. Springerplus 3(1), 1-10 (2014).

81. Kølle S-FT, Fischer-Nielsen A, Mathiasen AB et al. Enrichment of autologous fat grafts with ex-vivo expanded adipose tissue-derived stem cells for graft survival: a randomised placebo-controlled trial. Lancet 382(9898), 1113-1120 (2013).

82. Lo AT, Mori H, Mott J, Bissell MJ. Constructing three-dimensional models to study mammary gland branching morphogenesis and functional differentiation. J. Mamm. Gland Biol. Neoplasia 17(2), 103-110 (2012).

83. Choi JH, Bellas E, Vunjak-Novakovic G, Kaplan DL. Adipogenic differentiation of human adipose-derived stem cells on 3D silk scaffolds. In: Adipose-Derived Stem Cells Humana Press, Totowa, 702, 319-330 (2011).

84. Swamydas M, Eddy JM, Burg KJ, Dréau D. Matrix compositions and the development of breast acini and ducts in 3D cultures. In Vitro Cell. Development. Biol. Animal 46(8), 673-684 (2010).

85. Dai R, Wang Z, Samanipour R, Koo K-I, Kim K. Adipose-derived stem cells for tissue engineering and regenerative medicine applications. Stem Cells Int. 2016 6737-34519 (2016).

86. Arabpour Z, Baradaran-Rafii A, Lotfi Bakhshaiesh $\mathrm{N}$ et al. Design and characterization of biodegradable multi layered electrospun nanofibers for corneal tissue engineering applications. J. Biomed. Mat. Res. A 107(10), 2340-2349 (2019).

87. Amini N, Vousooghi N, Alizade A et al. Transplantation of adipose tissue-derived stem cells into brain through cerebrospinal fluid in rat models: Protocol development and initial outcome data. Curr. Stem Cell Res. Ther. 14(2), 191-195 (2019).

88. Sung H-J, Meredith C, Johnson C, Galis ZS. The effect of scaffold degradation rate on three-dimensional cell growth and angiogenesis. Biomaterials 25(26), 5735-5742 (2004).

89. Rnjak-Kovacina J, Wray LS, Burke KA et al. Lyophilized silk sponges: a versatile biomaterial platform for soft tissue engineering. ACS Biomat. Sci. Eng. 1(4), 260-270 (2015).

90. Nazarov R, Jin H-J, Kaplan DL. Porous 3-D scaffolds from regenerated silk fibroin. Biomacromolecules 5(3), 718-726 (2004).

91. Hu X, Shmelev K, Sun L et al. Regulation of silk material structure by temperature-controlled water vapor annealing. Biomacromolecules 12(5), 1686-1696 (2011).

92. Rockwood DN, Preda RC, Yücel T, Wang X, Lovett ML, Kaplan DL. Materials fabrication from Bombyx mori silk fibroin. Natureprotocols 6(10), 1612 (2011).

93. Lequeux C, Oni G, Wong C et al. Subcutaneous fat tissue engineering using autologous adipose-derived stem cells seeded onto a collagen scaffold. Plas. Reconstruct. Surg. 130(6), 1208-1217 (2012). 
94. Zachariah S, Low A, Pallua N. Influence of different biodegradable carriers on the in vivo behavior of human adipose precursor cells. Plas. Reconstruct. Surg. 108(2), 411-420 (2001).

95. Chhaya MP, Balmayor ER, Hutmacher DW, Schantz J-T. Transformation of breast reconstruction via additive biomanufacturing. Sci. Rep. 6, 28030 (2016).

96. Chhaya MP, Melchels FPW, Holzapfel BM, Baldwin JG, Hutmacher DW. Sustained regeneration of high-volume adipose tissue for breast reconstruction using computer aided design and biomanufacturing. Biomaterials 52, 551-560 (2015).

97. Zein I, Hutmacher DW, Tan KC, Teoh SH. Fused deposition modeling of novel scaffold architectures for tissue engineering applications. Biomaterials 23(4), 1169-1185 (2002).

98. Zhu J, Marchant RE. Design properties of hydrogel tissue-engineering scaffolds. Expert Rev. Med. Dev. 8(5), 607-626 (2011).

99. Wittmann K, Dietl S, Ludwig N et al. Engineering vascularized adipose tissue using the stromal-vascular fraction and fibrin hydrogels. Tissue Eng. Part A 21(7-8), 1343-1353 (2015).

100. Brandl FP, Seitz AK, Teßmar JK, Blunk T, Göpferich AM. Enzymatically degradable poly (ethylene glycol) based hydrogels for adipose tissue engineering. Biomaterials 31(14), 3957-3966 (2010).

101. Abberton K, Bortolotto S, Woods A et al. Myogel, a novel, basement membrane-rich, extracellular matrix derived from skeletal muscle, is highly adipogenic in vivo and in vitro. Cells Tissues Organs 188(4), 347-358 (2008).

102. Davidenko N, Campbell JJ, Thian E, Watson CJ, Cameron RE. Collagen-hyaluronic acid scaffolds for adipose tissue engineering. Acta Biomaterialia 6(10), 3957-3968 (2010).

103. Ahmed EM. Hydrogel: Preparation, characterization, and applications: a review. J. Adv. Res. 6(2), 105-121 (2015).

104. Krause S, Maffini MV, Soto AM, Sonnenschein C. A novel 3D in vitro culture model to study stromal-epithelial interactions in the mammary gland. Tissue Eng. C Meth. 14(3), 261-271 (2008).

105. Kaur P, Khaghani SA, Oluwadamilola A et al. Fabrication and characterizations of hydrogels for cartilage repair. Adv. Tissue Eng. Regen. Med. Open Access 2( 6), 283- 288 (2017).

106. Fathi A, Khanmohammadi M, Goodarzi A et al. Fabrication of chitosan-polyvinyl alcohol and silk electrospun fiber seeded with differentiated keratinocyte for skin tissue regeneration in animal wound model. 14(27),10.1186/s13036-020-00249-y (2020).

107. Nazeri N, Tajerian R, Arabpour Z et al. Bioinspired immobilization of carbon nanotubes on scaffolds for nerve regeneration. Bioinspired Biomimetic Nanobioma. 8(3), 198-205 (2019).

108. Saha S, Duan X, Wu L, Lo P-K, Chen H, Wang Q. Electrospun fibrous scaffolds promote breast cancer cell alignment and epithelial-mesenchymal transition. Langmuir 28(4), 2028-2034 (2011).

109. Mahjour SB, Sefat F, Polunin Y, Wang L, Wang H. Improved cell infiltration of electrospun nanofiber mats for layered tissue constructs. J. Biomed. Mat. Res. A 104(6), 1479-1488 (2016).

110. Xavier M, Macedo M, Benatti A et al. PLLA synthesis and nanofibers production: viability by human mesenchymal stem cell from adipose tissue. Procedia CIRP 49, 213-221 (2016).

111. Choi JS, Lee SJ, Christ GJ, Atala A, Yoo JJ. The influence of electrospun aligned poly (epsilon-caprolactone)/collagen nanofiber meshes on the formation of self-aligned skeletal muscle myotubes. Biomaterials 29(19), 2899-2906 (2008).

112. Nelson MT, Short A, Cole SL et al. Preferential, enhanced breast cancer cell migration on biomimetic electrospun nanofiber 'cell highways'. BMC Cancer 14(1), 825 (2014).

113. Yohe ST, Herrera VL, Colson YL, Grinstaff MW. 3D superhydrophobic electrospun meshes as reinforcement materials for sustained local drug delivery against colorectal cancer cells. J. Controlled Release 162(1), 92-101 (2012).

114. Krumboeck A, Giovanoli P, Plock JA. Fat grafting and stem cell enhanced fat grafting to the breast under oncological aspects-recommendations for patient selection. Breast 22(5), 579-584 (2013).

115. Krastev T, Jonasse Y, Kon M. Oncological safety of autologous lipoaspirate grafting in breast cancer patients: a systematic review. Ann. Surg. Oncol. 20(1), 111-119 (2013).

116. Zimmerlin L, Park TS, Zambidis ET, Donnenberg VS, Donnenberg AD. Mesenchymal stem cell secretome and regenerative therapy after cancer. Biochimie 95(12), 2235-2245 (2013).

117. Stensheim H, Cvancarova M, Møller B, Fosså SD. Pregnancy after adolescent and adult cancer: a population-based matched cohort study. Int. J. Cancer 129(5), 1225-1236 (2011).

118. Landrigan PJ, Sonawane B, Mattison D, Mccally M, Garg A. Chemical contaminants in breast milk and their impacts on children's health: an overview. Environ. Health Pers. 110(6), A313-A315 (2002).

119. Surendiran A, Balamurugan N, Gunaseelan K, Akhtar S, Reddy K, Adithan C. Adverse drug reaction profile of cisplatin-based chemotherapy regimen in a tertiary care hospital in India: an evaluative study. Ind. J. Pharmacol. 42(1), 40 (2010).

120. Fan L, Zhang Y, Wang F et al. Multifunctional all-in-one drug delivery systems for tumor targeting and sequential release of three different anti-tumor drugs. Biomaterials 76, 399-407 (2016). 
121. Goh Y-F, Shakir I, Hussain R. Electrospun fibers for tissue engineering, drug delivery, and wound dressing. J. Mat. Sci. 48(8), 3027-3054 (2013).

122. Mickova A, Buzgo M, Benada $\mathrm{O}$ et al. Core/shell nanofibers with embedded liposomes as a drug delivery system. Biomacromolecules 13(4), 952-962 (2012).

123. Saraf A, Baggett LS, Raphael RM, Kasper FK, Mikos AG. Regulated non-viral gene delivery from coaxial electrospun fiber mesh scaffolds. J. Controlled Release 143(1), 95-103 (2010).

124. Weldon CB, Tsui JH, Shankarappa SA et al. Electrospun drug-eluting sutures for local anesthesia. J. Controlled Release 161(3), 903-909 (2012).

125. Reagan MR, Kaplan DL. Concise review: mesenchymal stem cell tumor-homing: detection methods in disease model systems. Stem Cells 29(6), 920-927 (2011).

126. Khakoo AY, Pati S, Anderson SA et al. Human mesenchymal stem cells exert potent antitumorigenic effects in a model of Kaposi's sarcoma. J. Experimental Med. 203(5), 1235-1247 (2006).

127. Weigelt B, Bissell MJ. Unraveling the microenvironmental influences on the normal mammary gland and breast cancer. Presented at: Seminars in cancer biology. 18(5) 311-321 (2008).

128. Casadei A, Epis R, Ferroni L et al. Adipose tissue regeneration: a state of the art. Biomed. Res. Int. 2012, 462-543 (2012). 